\title{
Phenotype-dependent social associations among male sexual rivals in a polygamous fish, the Trinidadian guppy (Poecilia reticulata)
}

by Anne-Christine Auge

A thesis submitted to the Faculty of Graduate and Postdoctoral Affairs in partial fulfillment of the requirements for the degree

\section{Master of Science \\ in}

\section{Biology}

\author{
Carleton University \\ Ottawa, Ontario
}

(C) 2014

Anne-Christine Auge 


\begin{abstract}
Recent theory predicts that males should choose the social context that maximizes their relative attractiveness to females while minimizing sperm competition risk. By preferentially associating with less attractive and less competitive sexual rivals, a male may increase his reproductive success. Using the Trinidadian guppy (Poecilia reticulata), I tested for non-random social associations among males in mixed-sex groups based on two phenotypic traits (body length, body colouration) that predict relative sexual attractiveness to females. In a dichotomous-choice test, focal males exhibited a significant preference for mixed-sex groups that included a less colourful and smaller male rival, thereby potentially increasing their relative attractiveness, as predicted. However, this preference was not expressed in nature. Males in mixed-sex shoals in a natural stream population in Trinidad were not assorted by either body length or colour, perhaps owing to constraints placed on preferred social associations by sexual conflict and the fission-fusion nature of guppy shoals.
\end{abstract}




\section{ACKNOWLEDGMENTS}

First, I would like to express my sincere gratitude to my supervisor, Dr. Jean-Guy Godin, for his support and guidance before and during the time of my Master's research; for giving me the opportunity to spend this important part of my educational life at Carleton, for giving me the chance to conduct field and lab work in Trinidad, and to network with other researchers at a conference in Boulder, Colorado.

My appreciation is extended to my thesis advisory committee, for advice on my research when needed. I'd like to thank especially Dr. Tom Sherratt for patiently giving me advice on statistical analysis - more than once.

Further, I'd like to thank my lab mates for their help and for a good and fun time over the past two years. A special thanks goes to Heather Auld for her assistance in the lab and field (and life) in Trinidad, for always having time to answer any questions, and for moral support.

Lastly, I would like to thank my parents for their encouragement and always believing in me; and Paul Prior for his support and aiming to understand as much about my project as possible - which made me never lose the big picture of my research. 


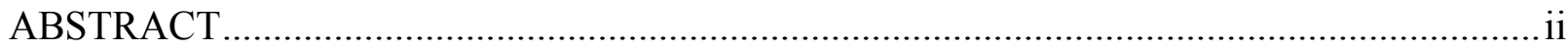

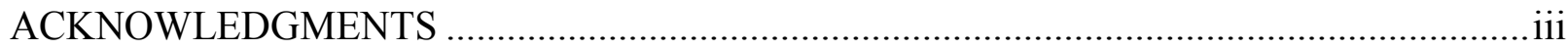



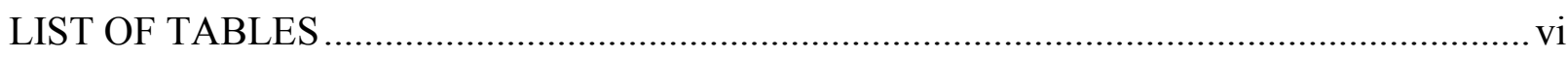

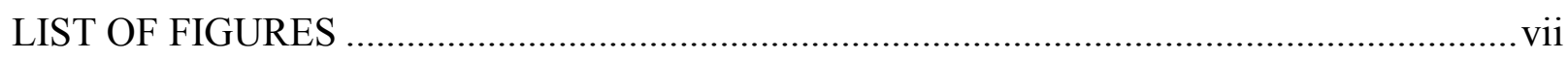

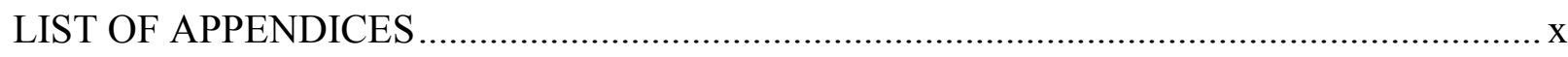

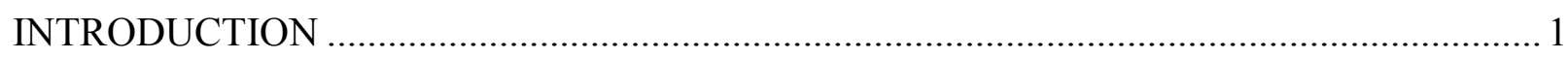

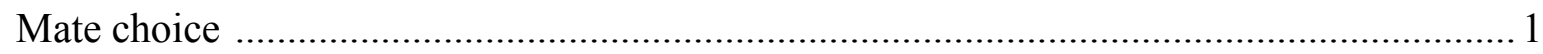

The importance of the social environment in mate choice ................................................... 3

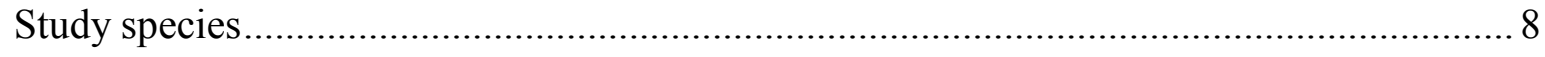

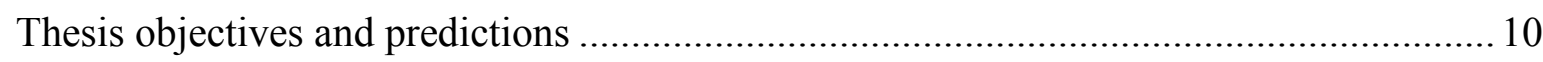

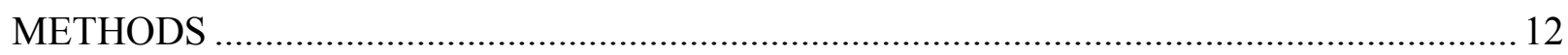

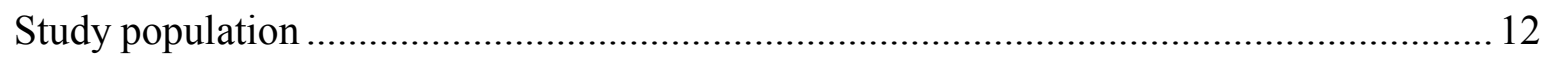

Part A: Testing for a shoal (social environment) preference in the laboratory .................... 12

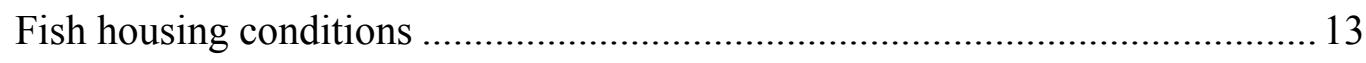

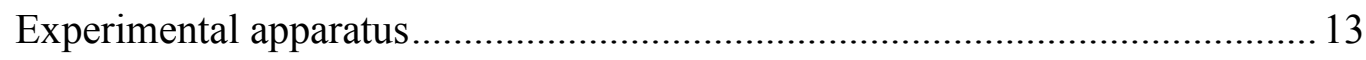

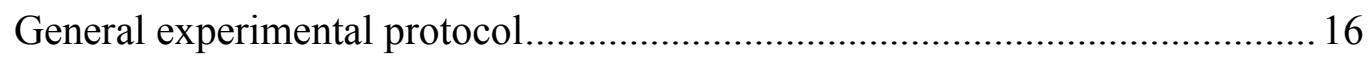

Body length and colouration measurements ...................................................... 19

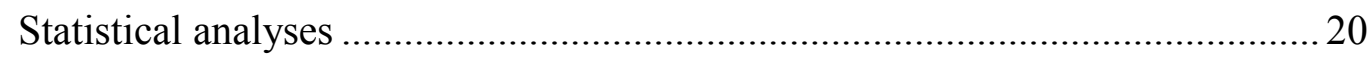

Part B: Testing for social associations among male guppies in the wild............................ 22






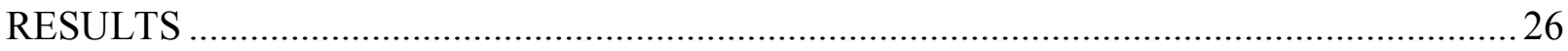

Relationship between male body length and colouration ...........................................26

Part A: Testing for shoal (social environment) preference in the laboratory .................. 31

Part B: Testing for social associations among male guppies in the wild ........................ 41

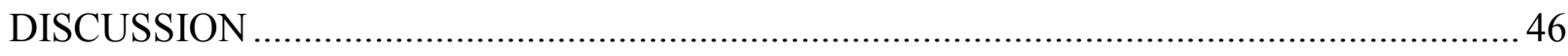

Social associations among male rival guppies in a dichotomous choice test ..................46

Social associations among male guppies in free-ranging shoals ...................................53

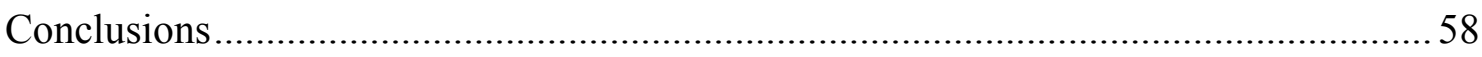

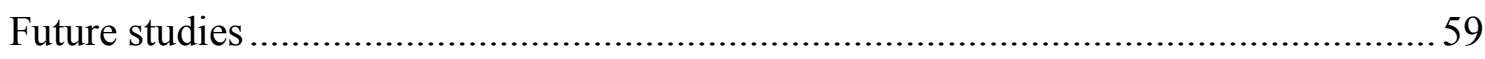

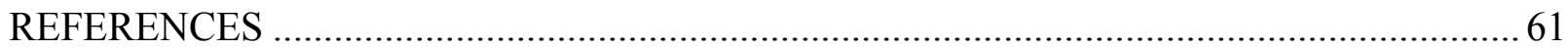

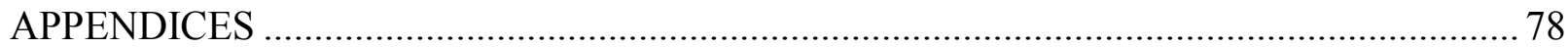




\section{LIST OF TABLES}

Table 1. Results of a multiple regression (following reduction using the Aikaike Information Criterion (AIC)) testing for the effects of absolute body length and colour score values of each male ('absolute hypothesis') on the time that focal males spent associating with their preferred mixed-sex stimulus shoal. Shown are the final model equation and the model's parameters, estimates, $\mathrm{p}$-values for each coefficient, multiple Rsquared and adjusted R-squared, and p-value....

Table 2. Results for the most parsimonious (best-fit), multiple regression model according to AICc (Model "M11" in Table A2) testing for the effects of the body length and colour differences between focal male and preferred stimulus male on the time that focal males spent associating with their preferred mixed-sex stimulus shoal. Shown are the final model equation and the model's parameters, estimates, p-values for each coefficient, multiple R-squared and adjusted R-squared, and p-value 


\section{LIST OF FIGURES}

Figure 1. Top-view schematic representation of the experimental apparatus, consisting of a central test aquarium holding the focal fish and two end compartments holding a stimulus male and female each. During the acclimation and viewing periods (totaling 20 minutes), the focal male (F) was held in a clear Plexiglas cylinder (represented by the stippled circle) in the centre of the test aquarium. The thick back line in each end compartment denotes an opaque Plexiglas partition, and the grey lines between the test aquarium and the end compartments represent removable opaque screens. The stippled lines denote the outer edge of each 10-cm wide preference zone in the test aquarium

Figure 2. Examples of variation in body colouration and body length in male guppies collected in the Upper Aripo River, Trinidad for use in the current study

Figure 3. Relationship between the total body lengths $(\mathrm{mm})$ and colour scores (proportion of body area coloured orange and black) of Upper Aripo River male guppies (a) used in the dichotomous choice tests in the laboratory (Pearson's correlation coefficient: $\left.\mathrm{r}=0.132, \mathrm{r}^{2}=0.0174, \mathrm{p}=0.0032, \mathrm{n}=495\right)$ and $(\mathrm{b})$ in captured free-ranging mixed-sex shoals in the field $\left(r=0.239, r^{2}=0.057, p=0.00136, n=177\right)$. The lines-ofbest fit were obtained from linear regression analysis

Figure 4. Frequency distribution of total body lengths of Upper Aripo River male guppies (a) used for the laboratory choice experiment $(\mathrm{n}=495)$, and (b) in captured freeranging mixed-sex shoals in the field $(n=177$.

Figure 5. Frequency distribution of body colour scores (proportion of body area coloured orange and black) of Upper Aripo River male guppies (a) used for the laboratory choice experiment $(\mathrm{n}=495)$, and (b) in captured free-ranging mixed-sex shoals in the field $(\mathrm{n}=177)$.

Figure 6. Mean time $( \pm \mathrm{SE})$ (in seconds) that the focal males $(\mathrm{n}=132)$ spent on the side of the test aquarium with the preferred mixed-sex shoal (representing more than $50 \%$ of the focal male's total association time spent on either side), and time that he was expected 
to spend with either mixed-sex shoal based on chance (i.e. expected $50 \%$ of time spent on both sides). Paired t-test on absolute association times: $\mathrm{t}=17.41, \mathrm{df}=131, \mathrm{p}<0.001$

Figure 7. Mean $( \pm$ SE) proportion of time that focal males $(n=132)$ spent associating with either the stimulus female or the adjacent stimulus male in the paired mixed-sex shoals. Paired t-test on absolute association times: $\mathrm{t}=-4.15, \mathrm{df}=131, \mathrm{p}<0.001$.

Figure 8. Two-dimensional heat diagram depicting the model-fitted association times (in seconds) spent by focal males near their preferred shoal in relation to the differences in body colouration (x-axis) and body length (y-axis) between the focal male and stimulus male in the former's preferred mixed-sex shoal. On the x-axis, the colour difference between focal and preferred stimulus male was plotted as a proportion of the focal male's colour score. The y-axis shows the body length difference between focal and preferred stimulus male as a proportion of the focal male's body length. The colour (heat) scale on the right denotes the dependent variable (association time of focal males), ranging from $400 \mathrm{~s}$ (white colour) to a maximum of $700 \mathrm{~s}$ (deep red). The blue lines represent the location of 0 on the $\mathrm{x}$ and $\mathrm{y}$ axes.

Figure 9. Three-dimensional heat diagram depicting the model-fitted association times (in seconds, y-axis) spent by focal males near their preferred shoal in relation to the differences in body colouration (x-axis) and body length (z-axis) between the focal male and stimulus male in the former's preferred mixed-sex shoal. On the x-axis, the colour difference between focal and preferred stimulus male was plotted as a proportion of the focal male's colour score. The z-axis shows the body length difference between focal and preferred stimulus male as a proportion of the focal male's body length. The colour (heat) scale on the right denotes the dependent variable (association time of focal males), ranging from $400 \mathrm{~s}$ (white colour) to a maximum of $700 \mathrm{~s}$ (deep red). The blue lines represent the location of 0 on the $\mathrm{x}, \mathrm{y}$ and $\mathrm{z}$ axes. This diagram shows the same results as in Figure 8, but in three dimensions rather than two dimensions

Figure 10. Probability density function of the theoretical F-distribution, with numerator $\mathrm{df}=66$ and denominator $\mathrm{df}=110$. The critical F-values for the lower $2.5^{\text {th }}$ percentile and upper $2.5^{\text {th }}$ percentile for a two-tailed test of the null hypothesis are shown in blue colour. 
The red vertical line indicates the actual calculated F-value obtained from an ANOVA comparing the within-group to between-group variation in the body length of male guppies present in free-ranging mixed-sex shoals $(n=67)$ that were collected in the Upper Aripo River, Trinidad.

Figure 11. Frequency distribution of F-values obtained from ANOVAs comparing the within-group to between-group variation in the body length of Upper Aripo River male guppies in 10,000 randomly simulated mixed-sex groups, as described in the Methods. The red vertical line indicates the actual calculated F-value obtained from an ANOVA comparing the within-group to between-group variation in the body length of male guppies present in free-ranging mixed-sex shoals $(n=67)$ that were collected in the Upper Aripo River, Trinidad. The red areas represent the lower and upper $2.5^{\text {th }}$ percentiles of the frequency distributions of the F-values for the 10,000 simulated groups

Figure 12. Probability density function of the theoretical F-distribution, with numerator $\mathrm{df}=66$ and denominator $\mathrm{df}=110$. The critical F-values for the lower $2.5^{\text {th }}$ percentile and upper $2.5^{\text {th }}$ percentile for a two-tailed test of the null hypothesis are shown in blue colour. The red vertical line indicates the actual calculated F-value obtained from an ANOVA comparing the within-group to between-group variation in the body colouration of male guppies present in free-ranging mixed-sex shoals $(n=67)$ that were collected in the Upper Aripo River, Trinidad.

Figure 13. Frequency distribution of F-values obtained from ANOVAs comparing the within-group to between-group variation in the body colouration of Upper Aripo River male guppies in 10,000 randomly simulated mixed-sex groups, as described in the Methods. The red vertical line indicates the actual calculated F-value obtained from an ANOVA comparing the within-group to between-group variation in the body colouration of male guppies present in free-ranging mixed-sex shoals $(n=67)$ that were collected in the Upper Aripo River, Trinidad. The red areas represent the lower and upper $2.5^{\text {th }}$ percentiles of the frequency distributions of the F-values for the 10,000 simulated groups ...... 46 


\section{LIST OF APPENDICES}

Table A1. Selection results for the candidate multiple regression models testing for the effects of body length and colour differences between the focal male, preferred stimulus male and non-preferred stimulus male ('relative hypothesis'), and the absolute colour scores for the three males ('absolute hypothesis'), on the time that focal males spent associating with their preferred mixed-sex stimulus shoal. The results are sorted by $\triangle \mathrm{AICc}$ values and AICc weights $\left(\mathrm{W}_{i}\right)$. The model set includes 11 models. Parameters that were the least significant were elminated, starting with the interaction terms, leading to a new model each.

Table A2. Results for the comparison (competing) multiple regression model (Model M2) testing for the effects of the absolute body lengths and colours of the non-preferred stimulus male and preferred stimulus male on the time that focal males spent associating with their preferred mixed-sex stimulus shoal. Shown are the model's equation and the model'sparameters, estimates, p-values for each coefficient, multiple R-squared and adjusted R-squared, and p-value

Table A3. Results of the AIC model selection process comparing two competing alternative models. One model (M11) tested for the effects of body length and colour differences between focal male and the preferred stimulus male on the time that focal males spent associating with their preferred mixed-sex stimulus shoal (dependent variable). The other model (M2) tested for the effects of the absolute length and colour scores of the non-preferred and preferred stimulus males on the dependent variable. The results are sorted by $\Delta \mathrm{AICc}$ values and AICc weights $\left(\mathrm{W}_{i}\right)$. Parameters that were the least significant were elminated, starting with the interaction terms, leading to a new model each 
Figure A1. Schematic diagram of pools sampled for mixed-sex shoals of guppies in the Upper Aripo River, Trinidad. The identification number and maximum linear dimensions (width $\mathrm{x}$ length, in metres) of each pool, and the distances (m) between them, are indicated. Shallow stream riffle sections separated adjacent pools. Arrows indicate the direction of water flow. The diagram is not to scale.

Figure A2. Proportion of adult males in free-ranging mixed sex shoals of guppies $(n=67)$ collected in the in the Upper Aripo River, Trinidad in relation to the total number of individuals (adult males + females) in the shoals. Line-of-best-fit was obtained by linear regression $(r=-0.698, p<0.05)$ 


\section{INTRODUCTION}

This thesis explores phenotype-dependent male-male associations within mixedsex groups, using body colouration and body length as indicators of male sexual attractiveness to females. The Introduction is divided into three sections. In the first section, I provide a general overview of mate choice, what its influences are and what effect an animal's decisions and social environment can have on mating success. In the second section, I briefly describe my model study species, the Trinidadian guppy (Poecilia reticulata), and its suitability for my current study. Finally, I provide a brief overview of the study's objectives and predictions.

\section{Mate choice}

Within-population differences among individuals in reproductive success depend on both competition between members of the same sex (intrasexual selection) and on the sexual attractiveness of individuals towards members of the opposite sex (mate choice or intersexual selection). Intersexual selection is an evolutionary process in which secondary sexual traits expressed by members of one sex which render them more likely to be chosen as mates by members of the opposite sex compared to others are selected for (Darwin, 1871; Andersson, 1994). Selection should favour individuals who find suitable mates that maximize their reproductive success over their lifetime (Andersson, 1994; Dugatkin, 2009). While intrasexual selection is more obvious in nature, intersexual selection tends to be more subtle but has received increasing interest over the past three decades (Andersson, 1994; Dugatkin, 2009). 
Mate choice involves decision making in both sexes and leads to non-random mating (Andersson, 1994). Both female and male mate choice occur in nature (Edward and Chapman, 2011). However, most previous studies have focused on female mate choice (e.g. Gerhardt, 1991; Andersson, 1994; Collins et al., 1994; Seehausen and Alphen, 1998). Choosy females are much more prevalent than males, because females generally invest more resources in reproduction and have lower reproductive potential than males (Clutton-Brock and Vincent, 1991, Andersson, 1994). Hence, there is more pressure for females to choose males of high quality (Andersson, 1994; Dugatkin, 2009). Yet, under some circumstances it pays for males to be choosy as well. Males may be choosy if they invest a lot of resources into searching for and courting females, breeding and/or parental care, if the operational sex ratio (OSR) is skewed towards males, if female availability is higher than the capacity to mate, and if females vary substantially in quality (i.e. fecundity, fertility, egg size) (Andersson, 1994; Parker et al., 1996; Edward and Chapman, 2011). For example, male zebra finches (Taeniopygia guttata) are able to distinguish between females differing in fecundity, and prefer the more over the less fecund one when given a choice (Jones et al., 2001). Female phenotypic traits that are reliable indicators of their reproductive quality include body size and age. In ectothermic species in particular, female fecundity is positively correlated with body size (e.g. Côté and Hunte, 1989; Honěk, 1993). For example, male red-sided garter snakes (Thamnophis sirtalis parietalis) preferentially court and mate with larger females that they distinguished from smaller ones via sexually attractive pheromones (LeMaster and Mason, 2002). 


\section{The importance of the social environment in mate choice}

The occurrence and intensity of mate choice can be influenced by certain environmental and/or social factors. For example, mate choice can vary geographically and temporarily, and can depend on predation risk or an individual's internal state for example (Forsgren, 1992; Andersson, 1994; Godin and Briggs, 1996; Baird et al., 1997; Fawcett and Johnstone, 2003; Punzalan et al., 2008). In social species, interactions between conspecifics may similarly influence mate choice and sexual selection (Jennions and Petrie, 1997). In a social context where there is a certain number of males and females present, a great variety of social interactions occurs. Male-male competition (intrasexual selection) is common and known to affect female choice (Jennions and Petrie, 1997). Further, in a population in which members of one sex differ in traits, attraction towards individuals with particular attractive traits is common (intersexual selection), as mentioned above (Andersson, 1994). Attraction and mate choice depend on the individuals being able to differentiate between members of the other sex (Dugatkin, 2009).

Indirect genetic effects (IGE) occur when genes expressed in one individual have an effect on the phenotype of social partners. Through IGE, traits that are expressed in one individual can thus affect the fitness of other individuals (Moore et al., 1997; Wolf et al., 1998), a process known as social selection (McGlothlin et al., 2010). For example, in the fruit fly (Drosophila melanogaster), social context influences the reproductive behaviour of group members. Females mate more often when males from various genetic strains are present in the group, and a male's reproductive success depends on both his strain and the strain of other males (Billeter et al., 2012). In the Cactus bug (Narnia 
femorata), the presence of females in the social environment influences the form and strength of sexual selection on males, such that male body size and area of sexuallydimorphic legs are more important in determining the outcome of male-male sexual competition when females are present than when absent (Procter et al., 2012).

The behaviour of individuals often depends on decisions they make on the basis of information they acquire from their physical and social environment (Valone and Templeton, 2002). Individual animals can obtain information from their environment through two potential pathways or mechanisms (Valone and Templeton, 2002; Danchin et al., 2004). One mechanism is referred to trial-and-error sampling, during which an individual obtains information directly by personally sampling or interacting with its environment (= personal information). The other mechanism is a process through which an individual obtains information about its environment indirectly by monitoring the behaviour of other individuals that interact with their environment (= social information). Social information can be direct signals, such as alarm calls (Seyfarth et al., 1980; Gouzoules et al., 1984), or by-products of the activities of others, so-called inadvertent social information (ISI) (Danchin et al., 2004). Public information (PI) is a form of ISI that provides information about the quality of resources (Danchin et al. 2004). PI is rich and reliable information for observers which reduces assessment time of an unknown environmental parameter and the uncertainty about its quality. For example, in the reproductive context, individuals are known to use PI to estimate the quality of potential available mates (Danchin et al., 2004; Valone, 2007).

In most species, individuals mate in the presence of other conspecifics (= observers) and thus have access to public information. In this social context, PI might 
then influence individual mating decisions, resulting in non-independent mate choice (Westneat et al., 2000; Valone and Templeton, 2002). One example of the latter is matechoice copying that has been documented in a number of polygamous fish and bird species in particular, and is more prevalent in females than males (Dugatkin and Godin, 1992; Westneat et al., 2000; Godin et al., 2005; Valone, 2007; Godin and Hair, 2009; Vakirtzis, 2011). In mate-choice copying, females observe the mating decisions of other females, which allows them to indirectly assess the quality of potential mates and then copy the observed mate choice of one of these conspecifics (Dugatkin and Godin, 1992, 1993; Kirkpatrick and Dugatkin, 1994; Godin et al., 2005).

Another form of non-independent mate choice is owing to the audience effect (Matos and Schlupp, 2005). An audience comprises one or more bystanding individuals who observe a social interaction between other individuals but are not directly involved in that interaction (Matos and Schlupp, 2005). It has been shown in several species that the presence of a nearby audience can alter the behaviour of an individual. An audience (e.g. of sexual competitors) can influence male mate choice in polygamous species (Plath et al., 2009; Ziege et al., 2009; Dubois and Belzile, 2012). More specifically, males can reduce their initial preference for a particular female when a nearby rival male, who may copy their mate choice, is in view (Dzieweczynski and Rowland, 2004; Makowicz et al., 2010; Ziege et al., 2009). In so concealing his true interest in a particular female, a focal male reduces his risk of sperm competition (Dosen and Montgomerie, 2004; Plath et al., 2008; Ziege et al., 2009) and also may avoid rejection by the preferred female (Plath et al., 2008; Dubois and Belzile, 2012). 
If the social context can influence the mate choice of individuals, then it can be expected that animals actively seek the social environment in which they can maximize their fitness. There are several studies suggesting that organisms can actively select, modify, construct, destroy and create their environment, thereby influencing local selection they experience in their environment (Bazzaz, 1991; Orians and Wittenberger, 1991; Odling-Smee et al., 1996; Laland et al., 1999; Lewis, 2008). Thus, the behavioural decisions made by individual animals can mediate evolutionary change (Sol et al., 2005; Duckworth, 2009). For example, theory predicts that males should prefer females (even relatively low-quality ones) that are surrounded by poorer competitors so as to minimize costly male-male sexual competition (Fawcett and Johnstone, 2003). Further, Dugatkin and Sargent (1994), who defined male sexual attractiveness as proximity to females, showed that male guppies preferred to socially associate with conspecific males that were presumably less attractive (i.e. were further away from females) than themselves.

Recently, Oh and Badyaev (2010) showed that wild male house finches (Carpodactus mexicanus) with relatively dull plumage move between social groups more frequently (i.e. are more socially labile) than more ornamented (colourful) males. The less ornamented males chose to occupy social groups in which they appeared more attractive relative to rival males, thereby potentially increasing their own mating success. Relatively unattractive males can benefit from associating with more attractive males either because the group experiences an increased number of female visits in general (Beehler and Foster, 1988), or because the focal male actually increases his relative attractiveness to females and thus his mating success (Bateson and Healy, 2005). Since the process of habitat selection is not entirely cost free (e.g. Stamps et al., 2005), dull- 
plumage males might benefit most from selecting their social environment in terms of mating success and therefore are expected to show the greatest investment in social lability (Badyaev and Qvarnström, 2002; Oh and Badyaev, 2010).

When individual males make decisions about which male social partners to associate with, there are at least three possible alternative outcomes (Dugatkin and Sargent, 1994). First, an individual male might not be able to assess his relative attractiveness, or ignores it, when choosing with whom to associate socially. Second, an individual male might associate with relatively more attractive conspecific males in order to increase the number of females attracted to him and thereby increase his chances of mating (presumably mainly through sneak copulations). Third, an individual male might prefer to associate with relatively less attractive conspecific males to increase his chances of being the male chosen by female(s) as the apparently more attractive male in the group. All three of these proposed possibilities may increase a focal male's mating success (Dugatkin and Sargent, 1994).

Following on the study of Oh and Badyaev (2010), I investigated in the current study whether wild male Trinidadian guppies associate with each other non-randomly based on their respective phenotypes. Guppies are highly social fish that live in shoals of varying size and composition in nature (Magurran, 2005). Shoaling in fishes has evolved primarily as an anti-predator adaptation that reduces individual risk of predation (Godin 1986). Additional individual fitness benefits associated with social group living include enhanced foraging success, reduced energetic costs of movement and enhanced encounter rate with potential mates (Krause and Ruxton, 2002). Individuals in groups are generally not randomly assembled (Krause and Ruxton, 2002). Group living and the group's 
membership composition are likely based on individual behavioural decisions (Krause and Ruxton, 2002; Croft et al., 2003a). Fish assort themselves by body size within a shoal and commonly occur in multiple size-assorted shoals in nature (Pitcher et al., 1986; Krause et al., 2000; Ward and Krause, 2001; Croft et al., 2003a). Moreover, individuals of some species/populations prefer to socially associate with familiar conspecifics (e.g. female guppies, Magurran et al., 1994; Griffiths and Magurran, 1997a, 1997b).

\section{Study species}

I used the Trinidadian guppy as my study system for the following reasons. The guppy is an internally-fertilizing, live-bearing poeciliid fish native to fresh-water streams and rivers in Trinidad and Tobago and adjacent regions of South America (Houde, 1997; Magurran, 2005). Guppies live in mixed-sex shoals in nature and exhibit a non-resourcebased promiscuous mating system (Houde, 1997; Magurran, 2005). Females are usually multiply-mated by several males and can store sperm for up to six months after insemination (Kelly et al., 1999; Neff et al., 2008). Guppies are a classic example of a species that has evolved sexual dimorphism and conspicuous traits in males as a result of sexual selection (Houde, 1997; Magurran, 2005). Adult females are significantly larger than adult males. Complex colour patterns, consisting of black (melanin) and red-orangeyellow carotenoid-pigmented spots and iridescent coloured (white, green, blue) areas, are only expressed in adult males. Males exhibiting conspicuous colour patterns and high levels of courtship displays are favoured as sexual partners by females (Houde, 1997). The amount (surface area) and saturation of carotenoid (yellow, orange, red) colouration, 
as well as black spots in some populations, in the skin of male guppies, the visual contrast of their body colouration pattern, the area of their caudal fin and their body length are positively correlated with male sexual attractiveness and mating success (Reynolds and Gross, 1992; Endler and Houde, 1995; Houde, 1997; Brooks and Endler, 2001; Herdman et al., 2004). Thus, female guppies tend to prefer mating with the more brightly coloured and/or larger of available males.

Males are mainly preoccupied with sexually pursuing, courting and mating with females in nature (Houde, 1997; Magurran, 2005). An alternative and less energetically costly mating strategy of males, apart from courtship displays, is sneak-copulation or gonopodial thrusting (Houde, 1997; Magurran, 2005). Guppies further provide a good example of mate choice copying, whereby females can base their mating decisions on the preference of other females they observed (Dugatkin and Godin, 1992, 1993; Godin et al., 2005; Godin and Hair, 2009).

In addition to female mate choice, guppies also exhibit male mate choice (Herdman et al., 2004; Jeswiet and Godin, 2011; Godin and Auld, 2013). Since adult females vary widely in quality (size, fecundity, reproductive state and receptivity) (Reznick and Endler, 1982) and male mating effort is costly (Houde, 1997; Kelly et al., 1999; Jeswiet et al., 2011), males are selected to be choosy as well.

Owing to their shoaling behaviour (Magurran, 2005), aggregation into smallworld social networks (Croft et al., 2004, 2009b, 2012) in the wild and their promiscuous mating system (Houde, 1997), guppies are constantly surrounded by conspecifics (that form their social environment) in nature, which can in turn influence the behavioural 
decisions of individuals. Guppies are sensitive to their social environment and the courtship behaviour of males can be affected by the presence and behaviour of other males nearby, the ambient sex ratio, and the composition of their social group (Houde, 1997; Jirotkul, 1999; Makowicz et al., 2010; Jeswiet et al., 2012). Moreover, males vary widely in phenotype (particularly behaviour, body length and body colouration) within and between populations (Endler, 1980, 1983; Houde, 1997; Magurran, 2005). For these reasons, the Trinidadian guppy is an ideal model species for investigating phenotypedependent social associations among male sexual competitors within populations.

\section{Thesis objective and predictions}

The general objective of my study was to investigate patterns of social associations among rival male guppies and to test whether males are assorted into social groups non-randomly based on certain phenotypic traits known to be sexually selected. I focused on two male secondary sexual traits as indicators of sexual attractiveness, namely, body colouration (proportion body area covered by carotenoid and melanin spots) and total body length, that male guppies might potentially assess and use to assort themselves socially into groups whilst searching for and sexually pursuing females. My study comprised two inter-related projects, with the first project being a laboratory experiment and the second one consisting of field observations on, and collections of, free-ranging mixed-sex shoals of guppies to test for non-random social assortativeness.

I first conducted a laboratory dichotomous-choice experiment to test whether individual focal males prefer one or the other of two mixed-sex social groups, each 
consisting of a female and a male sexual rival who is either more or less attractive than itself (based on differences in their body colouration and body length). A priori predictions were difficult to make since there are three potential outcomes: (i) the focal male guppy could choose to prefer the social group that comprises the less attractive stimulus male in order to appear relatively more attractive, (ii) he could prefer the social group that comprises the more attractive stimulus male so as to attract additional females into the focal group and thereby increase opportunities for sneak copulation, or (iii) associations between focal and rival males could be random with respect to their body colouration and length.

Based on the findings of this laboratory experiment (see Results section below), I performed visual focal observations and collections of free-ranging guppy shoals in a river in Trinidad to test whether males occurring in mixed-sex shoals are assorted by body colouration and/or body length and to ascertain whether any male social association preferences observed in the laboratory (Experiment 1) are expressed in nature. I namely addressed the question: Do wild male guppies occur in mixed-sex groups that are assorted by either male body length or body colouration more so than expected by chance? Males that occur in mixed-sex groups in nature could be either negatively assorted (choose to associate with rival males of dissimilar phenotype), positively assorted (choose to associate with rivals of similar phenotype) or not assorted phenotypically based on body colouration or length. 


\section{METHODS}

\section{Study population}

The current study was conducted on wild Trinidadian guppies from the Upper

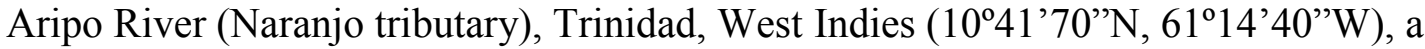
low-predation population (Magurran, 2005), between April and June 2013 in the dry season. Since predation risk can affect the expression of conspicuous phenotypes, male guppies that have evolved in populations experiencing relatively low predation pressure are on average larger and more colourful than males in populations experiencing high predation pressure in Trinidad (Endler, 1983; Magurran, 2005). Males in the Upper Aripo River population vary widely in both body length and colouration (see Results section, Figs. 2-5 below).

\section{Part A: Testing for a shoal (social environment) preference in the laboratory}

The aim of this experiment was to investigate, using a dichotomous-choice paradigm (Jeswiet and Godin, 2011), any preferences of adult focal male guppies to associate socially with either of two simultaneously presented mixed-sex stimulus shoals, each comprising of one adult stimulus female and one adult rival male guppy. The two stimulus females were size-matched and each placed in proximity to a stimulus male that was either of similar, higher or lower attractiveness (total body length and body colouration) than the focal male. 


\section{Fish housing conditions}

The guppies used in this experiment were collected haphazardly by hand seining in the Upper Aripo River. The collected fish were transported in buckets to a laboratory at the University of the West Indies (St. Augustine campus), Trinidad and held in mixedsex aquaria filled with aged tap water $\left(24-26^{\circ} \mathrm{C}\right)$ and exposed to overhead fluorescent lighting and diffused natural sunlight on a $12 \mathrm{~h} \mathrm{~L}: 12 \mathrm{~h}$ D cycle. They were fed commercial flake food and live brine shrimp (Artemia sp.) twice daily. All collected fish were treated with preventative anti-parasite (LifeBearer $\left.{ }^{\circledR}\right)$ and anti-fungal (APICMelafix $\left.{ }^{\circledR}\right)$ medication. Only fish that appeared healthy were used in behavioural trials. Wild-caught guppies were acclimatized to these laboratory holding conditions for at least one day post-capture prior to being used in behavioural trials.

\section{Experimental apparatus}

The experimental apparatus consisted of a central Plexiglas aquarium (40 x $20 \times 25 \mathrm{~cm}$; L x W x H), flanked by a clear Plexiglas compartment $(15 \times 20 \times 25 \mathrm{~cm})$ on each end (Fig. 1). The area within $10 \mathrm{~cm}$ from each end of the test aquarium was delineated as a preference zone. The central test aquarium held a focal male, and each of the two end compartments held one stimulus rival male and one stimulus female, separated by an opaque Plexiglas partition to prevent interactions between them. The two stimulus males were placed diagonally across from each other in the two end compartments (Fig. 1). This arrangement of holding each fish in separate compartments allowed for testing of the mating/association preference of the focal male 
based on visual cues only. The bottom of the central test aquaria and end compartments was covered with natural river gravel. The back wall of the test aquarium and three sides of each of the end compartments were covered with brown paper to reduce any external disturbances for the test fish. The front open side of the central test aquarium was covered with a brown cardboard blind, equipped with a small viewing window, from behind which I could observe the fish undisturbed. The apparatus was illuminated overhead as for the holding aquaria. 


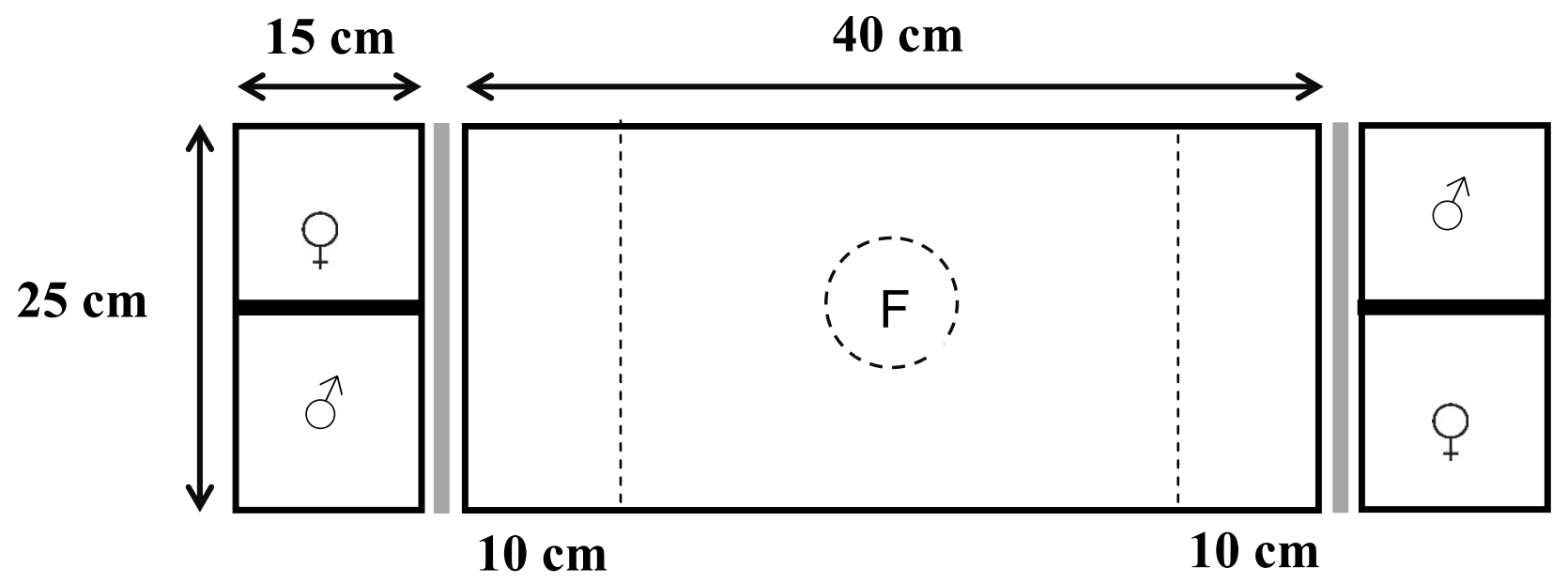

Figure 1. Top-view schematic representation of the experimental apparatus, consisting of a central test aquarium holding the focal fish and two end compartments holding a stimulus male and female each. During the acclimation and viewing periods (totaling 20 minutes), the focal male (F) was held in a clear Plexiglas cylinder (represented by the stippled circle) in the centre of the test aquarium. The thick back line in each end compartment denotes an opaque Plexiglas partition, and the grey lines between the test aquarium and the end compartments represent removable opaque screens. The stippled lines denote the outer edge of each $10-\mathrm{cm}$ wide preference zone in the test aquarium. 


\section{General experimental protocol}

In nature, male Trinidadian guppies sexually pursue females within small mixedsex groups or shoals comprising most commonly of one or more females and one rival male (Jeswiet et al., 2011; also see Results, Part B below). Therefore, in this experiment, I attempted to simulate such a natural sexually-competitive social context by presenting individual focal males with a dichotomous simultaneous choice between a shoal of one stimulus male and one stimulus female in one of the end compartments of the test apparatus and another shoal consisting of a different stimulus male and stimulus female in the other end compartment (Fig. 1), with the particular end compartments for each stimulus shoal determined at random. In any given behavioural trial, the two stimulus females were matched for body length $(\leq 1 \mathrm{~mm})$ and were gravid (pregnant) and thus sexually unreceptive (Houde, 1997), so as to standardized their reproductive state and thus ensure that male mate choice would not be confounded by female sexual responses to male sexual activity (Dosen and Montgomerie, 2004; Jeswiet and Godin, 2011). Although most adult female guppies in natural populations in Trinidad are mated and pregnant at any given time (Houde, 1997), males nonetheless sexually pursue, court and attempt to mate with previously-mated gravid females in both the wild and in laboratory (Guevara-Fiore et al., 2010; Houde, 1997; Jeswiet et al., 2011) and can successfully inseminate unreceptive gravid females through forced sneak copulations (Pilastro and Bisazza, 1999; Evans et al., 2003) and sire offspring (Kelly et al., 1999; Herdman et al., 2004; Neff et al., 2008). The two stimulus males were chosen to differ in either their total body length or amount of body colouration and thus their relative sexual attractiveness to females (Houde, 1997). Since guppies can become familiar with each other after 12 days of association (Griffiths and Magurran, 1997a) and social familiarity can potentially 
affect male mate choice (Hughes et al., 1999; Kelley et al., 1999), the focal male, stimulus males and stimulus females used in any given trial were taken from different holding aquaria and were presumably unfamiliar with each other prior to testing.

In choosing focal and stimulus males for my behavioural trials, I aimed to represent the natural range of body lengths and colouration of free-ranging males in the Upper Aripo River (see Results, Figs. 4 and 5 for validation) and to present each focal male with two rival stimulus males that were either similar or different in body length and colouration relative to each other and to the focal male. To do so, in about half the trials, I presented focal males with paired stimulus males that were similar in body length but different in overall body colouration and, in the other half of the trials, the paired stimulus males were relatively similar in overall body colouration but different in body length. On average, focal males were intermediate in body length and colouration between the paired stimulus males and thus near the median for both traits in Upper Aripo River males. When choosing the three males for each trial and prior to placing them into the apparatus, I initially measured them (without anaesthesia) using a metric measuring board and categorized their overall body colouration by eye as either similar, more colourful or less colourful relative to each other. At the end of the experiment, the body length and colouration of each male were more accurately measured using digital photographs on the males (Fig. 2, and see below).

All trials followed the same procedure. At the outset of a trial, opaque screens were placed between the end compartments and the test aquarium (Fig. 1). The focal male was then placed in a clear Plexiglas cylinder (7-cm diameter) in the centre of the test aquarium and the stimulus males and females placed in their respective halves of the 
end compartments (Fig. 1). Whilst out of view of one another, the fish were allowed to acclimatize to the aquarium environment for 10 minutes. After this period and with the focal male still in the central cylinder, the opaque screens were removed and the focal male was allowed to view both mixed-sex stimulus shoals in their respective end compartments for another 10-minutes. At the end of this viewing period, the cylinder was gently raised and the focal male was allowed to freely choose to associate with either of the stimulus shoals for 15 minutes. To minimize any external disturbances, the fish were filmed using a video webcam (Logitech HD Pro Webcam C910) placed approximately $30 \mathrm{~cm}$ above the test aquarium. The video footage was displayed and observed in real time on the screen of a laptop computer located adjacent to the test apparatus. The water in the test aquarium and end compartments was changed with fresh aged water after every completed trial.

For each trial, the time that the focal male spent associating with (i.e. within $\leq 10 \mathrm{~cm}$ of) either stimulus shoals was quantified using JWatcher ${ }^{\mathrm{TM}}$ (Blumstein and Daniel, 2007). More specifically, the time that the focal male spent within the preference zone, and directly in front, of the stimulus females and the adjacent stimulus male separately was quantified, as a measure of his preference of either mixed-sex stimulus shoal. Such association or proximity time is a commonly used proxy for social attractiveness (Godin et al., 2003; Song et al., 2011) and mating preferences in poeciliid fishes (Bisazza et al., 1989; Dosen and Montgomerie, 2004; Plath et al., 2008; Jeswiet et al., 2011), and is a strong predictor of sexual activity and mate choice in male guppies (Dugatkin and Godin, 1992; Jeswiet and Godin, 2011). 
I similarly tested a total of 132 focal males that 'sampled' both stimulus shoals (entered both preference zones and spent time in front of both stimulus females and stimulus males) during the 15-min observation period. Because of the limited availability of males, some focal males were re-used as stimulus males; however, no male was used more than once as a focal male. At the end of the experiment, only healthy fish were returned live to the Upper Aripo River; the remaining (suspected of bacterial or fungal infection) were euthanized.

\section{Body length and colouration measurements}

After each trial, all five fish were lightly anaesthetized (with MS-222 at 1:10,000 dilution), placed on a piece of white Plexiglas, and their left side digitally photographed with an Olympus ${ }^{\mathbb{O}}$ camera (Stylus Tough-6000) along with a metric scale.

The total body length $(\mathrm{mm})$ of each test fish and the body colour score of each male were later quantified from their photographs using Image $^{\odot}$ (http://rsb.info.nih.gov/ij/). The total area of each male's body (excluding the fins) and the areas of melanin (black) and carotenoid (yellow, orange, red pigments; hereafter collectively referred to as "orange") spots on his left side were quantified. A male's colouration pattern was expressed as the proportion of its body (excluding fins) covered by colour (black, yellow, orange, red), which is referred to hereafter as a male's "colour score". A few focal males had no detectable black or carotenoid colour spots on their body; these males were assigned a non-zero colour score of 0.001 to facilitate statistical analyses. Males with longer body lengths and higher colour scores were deemed more 
sexually attractive than smaller and duller males, because female Trinidadian guppies tend to prefer larger and more colourful males as mates (Reynolds and Gross, 1992; Endler and Houde, 1995; Houde, 1997; Brooks and Endler, 2001; Herdman et al., 2004).

The body length and colour scores of all fish used in this study (Part A and Part B; $n=672$ ) were measured twice and their averages used in further analyses (Pearson's correlation coefficient for repeated measures: $\left.\left.\mathrm{r}_{(\text {colour scores }}\right)=0.918, \mathrm{r}_{(\text {body length })}=0.955\right)$.

\section{Statistical analyses}

I first ascertained whether focal males exhibited any preference for either of the stimulus mixed-sex shoals by comparing the association times that each male spent with his preferred shoal against that expected by chance (i.e. at random) using the paired t-test. A shoal preference was defined as a focal male spending more than $50 \%$ of its total association time near one or the other of the two stimulus shoals. Given that focal males exhibited a shoal preference (see Results, Part A), I then used linear models (i.e. multiple regression analyses) to test for the main effects of the body length and colour scores of the stimulus males, and their interaction, on the preference of focal males (as measured by association time) for either of the mixed-sex stimulus shoals presented. A number of analytical steps were sequentially carried out as follows.

First, a general inclusive model was constructed, with the absolute values for body colouration (proportion of body area covered with pigment colours) and total body length (mm) of the focal male and the two stimulus males in a trial as independent (explanatory) variables, the body lengths of the stimulus females as co-variables, and the focal male's 
absolute association time (in seconds) spent near the preferred stimulus shoal as the dependent variable, to ascertain which, if any, of the independent variable(s) accounted for a significant portion of the observed variation in the focal males' social association preferences.

Second, to evaluate whether the social preferences of focal males were influenced by the absolute values or relative differences in male body colour and body length, an alternative competing model was constructed. This model included as explanatory variables the relative colour and length differences between the focal males and both stimulus males, and between the two stimulus males, as well as the absolute colour scores of all three males, since the first model showed that colour had a significant effect on focal male social preferences (see Results section). In the second model, colour and length differences were either relative to the focal male or to the non-preferred stimulus male. Both models were sequentially reduced (by removing non-significant variables, beginning with non-significant interaction terms) to identify the qualitatively best explanatory and most parsimonious one using the Akaike Information Criterion (AIC) (Akaike, 1974).

Finally, the reduced (most parsimonious) model yielded from the above second step was compared against a model with only the absolute colour scores and body lengths of both stimulus males, again using AIC, to confirm whether variation in observed focal male preferences is best explained by phenotypic differences between focal and preferred stimulus male or by the absolute phenotype of either stimulus male. 
All statistical tests were carried out in the $\mathrm{R}$ statistical environment ( $\mathrm{R}$ Development Core Team, 2013).

\section{Part B: Testing for social associations among male guppies in the wild}

Given that my laboratory experiment (Part A) revealed that individual male guppies exhibited a preference for mixed-sex shoals that comprised a female in proximity to a sexually less attractive (i.e. smaller and less colourful) rival male than themselves (see Results section), the aim of this second part of the thesis was to test whether such a social preference was expressed by free-ranging males in the wild (i.e. in the Upper Aripo River, Trinidad). More specifically, I tested whether wild male guppies associate nonrandomly with other males in mixed-sex groups based on their relative body length and/or colour.

\section{Collection of free-ranging guppy shoals}

Observations of free-ranging guppy shoals in the Upper Aripo River were made between 09:00 and 15:00 hrs from vantage points on the shoreline of six small pools along a 100-m stretch of the river on 10 days between 24 April and 17 June, 2013. The pools were shallow ( $<1 \mathrm{~m}$ depth), ranged in surface area from approximately 1 to $49.5 \mathrm{~m}^{2}$ and were between 1 and $41 \mathrm{~m}$ apart from each other (see Appendix Fig. A1). Each pool was visually scanned for the presence of mixed-sex guppy shoals that consisted of two or more males sexually pursuing at least one female within the shoal (cf. 
Jeswiet et al., 2011). Each visually-localized focal shoal (defined as fish within three body lengths of each other; Pitcher and Parrish, 1993) was captured in its entirety with a hand seine $(3 \mathrm{~m} \times 1 \mathrm{~m})$ and placed in a bucket containing river water. Males and females in each collected shoal were then enumerated and each male was lightly anaesthetized (with MS-222 at 1:10,000 dilution), placed on a piece of white Plexiglas alongside a metric scale and his left side photographed with a digital camera. Following photography, the captured fish were retained in buckets with aerated river water and only released back into the river (at the site of their collection) at the end of the day to avoid re-capture and pseudo-replication. To provide sufficient time for fish to move within and between pools and to reconstitute social associations between samples and thus to further minimize the likelihood of pseudo-replication, I collected a maximum of two focal shoals per pool per sample day, one in the morning and one in the afternoon (separated by a minimum of $2 \mathrm{~h}$ ). Wild guppies move more within than between pools, and males are more mobile than females (Croft et al., 2003a, 2003b). A total of 67 focal mixed-sex shoals were collected. Based on my visual inspections of the photographs of all males collected $(\mathrm{n}=$ 177) and the data on their individual lengths and colour scores, I could not detect any males that are identical phenotypically. Therefore, I am confident that I did not repeatedly capture the same male(s) in my shoal collections and that my field-based data (see Results below) are not pseudo-replicated. 


\section{Statistical analyses}

The total body length and body colouration pattern of individual males that occurred in the collected mixed-sex shoals were quantified from their photographs (e.g.

Fig. 2) using $\operatorname{ImageJ}^{\mathcal{C}}$, as described above for the laboratory experiment (Part A). I first tested whether males observed sexually pursuing females together in small shoals in the wild were more or less assorted either by body length or body coloration than expected by random association (i.e. chance) by comparing inter-male variation in both body length and colour within shoals to the between-shoal variation in these two traits using the F-statistic obtained from a one-way analysis of variance (ANOVA). I then investigated whether the calculated F-values obtained from the data on male body length and colouration respectively differed from the F-value expected by chance by comparing the observed F-values for body length and colour scores to the theoretical F-distribution as follows. I simulated 10,000 random guppy shoals using MATLAB (R2013a, The MathWorks). In the simulations, the number of wild guppy shoals collected $(n=67)$ and the membership size of each shoal were conserved, and all individual males (and thus their respective body length and body colouration scores) in the collected wild shoals were randomly shuffled and assigned to newly-formed simulated shoals. That is, malemale associations within shoals were randomized and reshuffled across all 67 shoals during each simulation run. For each of the 10,000 simulated shoals, an F-statistic value for male body length and colouration separately was calculated using the ANOVA as described above. The observed F-values for the body length and colouration of males occurring in the collected wild shoals were then compared to the frequency distribution of the 10,000 simulated F-values for each of the two phenotypic traits separately using R. 
For a two-tailed test, an observed value of the F-statistic must fall in either the lower or upper $2.5 \%$ of the distribution of simulated values for the rejection of the null hypothesis that the observed associations of wild male guppies in mixed-sex shoals, based on either their body length or colouration, was generated by chance (cf. Croft et al., 2008). 


\section{RESULTS}

\section{Relationship between male body length and colouration}

Both total body length and colouration varied widely (Figs. 2 - 5) among Upper Aripo male guppies, and their respective frequency distribution approximated a normal distribution (Figs. 4 and 5). Body length and colour scores of individual males correlated positively and significantly for both the fish used in the laboratory experiment (Part A, Pearson's correlation coefficient, $\mathrm{r}=0.132, \mathrm{p}=0.0032, \mathrm{n}=495)$ and for fish collected in the field to test for assortative shoaling (Part $\mathrm{B}, \mathrm{r}=0.239, \mathrm{p}=0.0013, \mathrm{n}=177$; Fig. 3). Although significant statistically, a considerable amount $(>95 \%)$ of the observed variation in these two phenotypic traits is not explained by linear regression models (Fig. 3) and therefore body length is not a strong predictor of body colouration in Upper Aripo male guppies.

The average body length and colouration score of males used in the laboratory choice experiment was $25.2 \mathrm{~mm}(\mathrm{SE}=0.09$, range $=19.8-31.9$; Fig. 4a $)$ and 0.061 $(\mathrm{SE}=0.001$, range $=0.001-0.150 ;$ Fig. $5 \mathrm{a})$, respectively, compared with $24.8 \mathrm{~mm}$ $(\mathrm{SE}=0.12$, range $=18.9-29.8 ;$ Fig. $4 b)$ and $0.062(\mathrm{SE}=0.002)$, and ranged from $0.001-0.137$; Fig. 5b) for the males collected in free-ranging mixed-sex shoals. Given these similarities, the body length and colouration of the male guppies used in the laboratory choice experiment are therefore representative of the phenotypic traits of the males collected in free-ranging mixed-sex shoals, and presumably of the population at large, in the Upper Aripo River. 

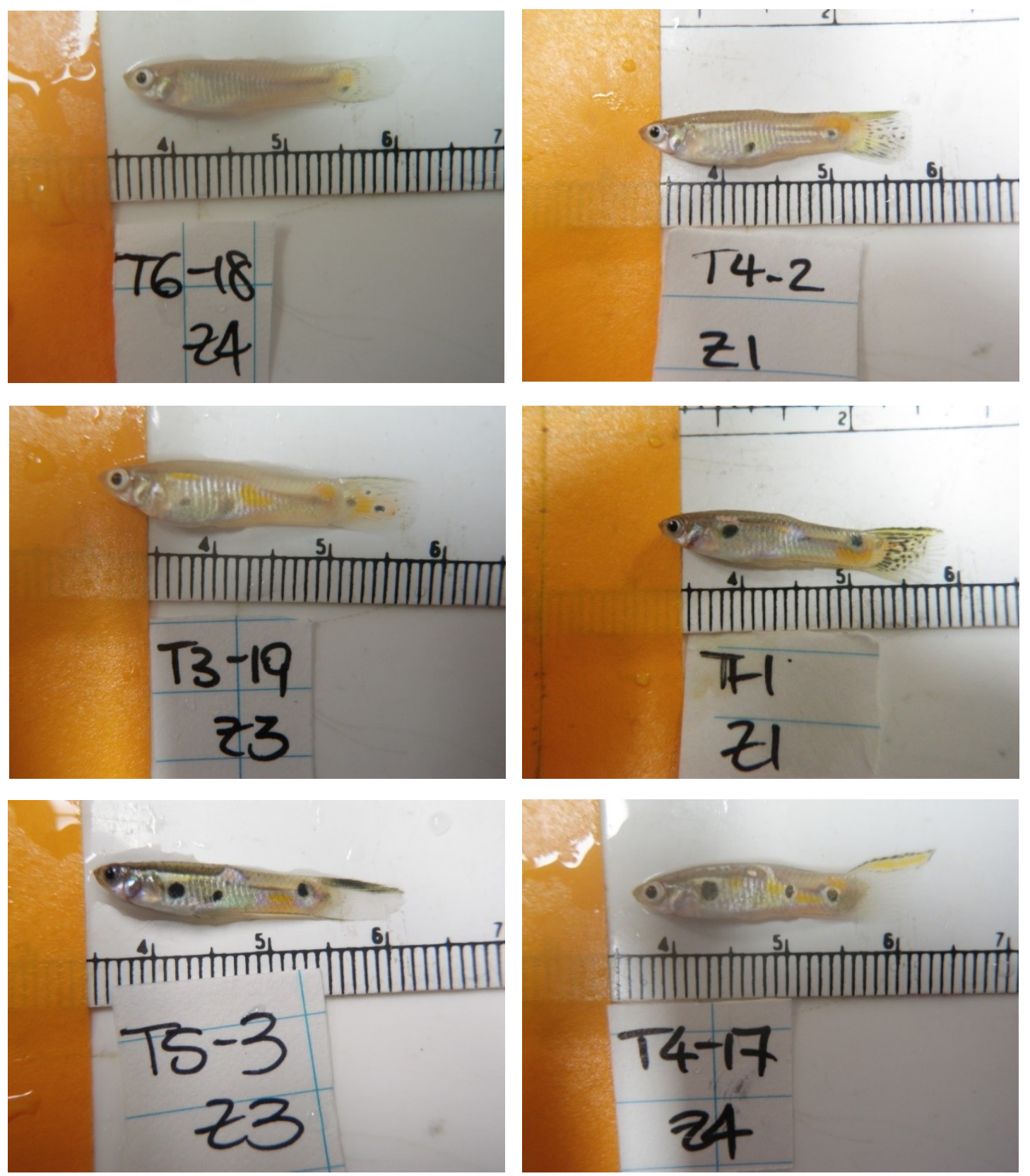

Figure 2. Examples of variation in body colouration and body length in male guppies collected in the Upper Aripo River, Trinidad for use in the current study. 

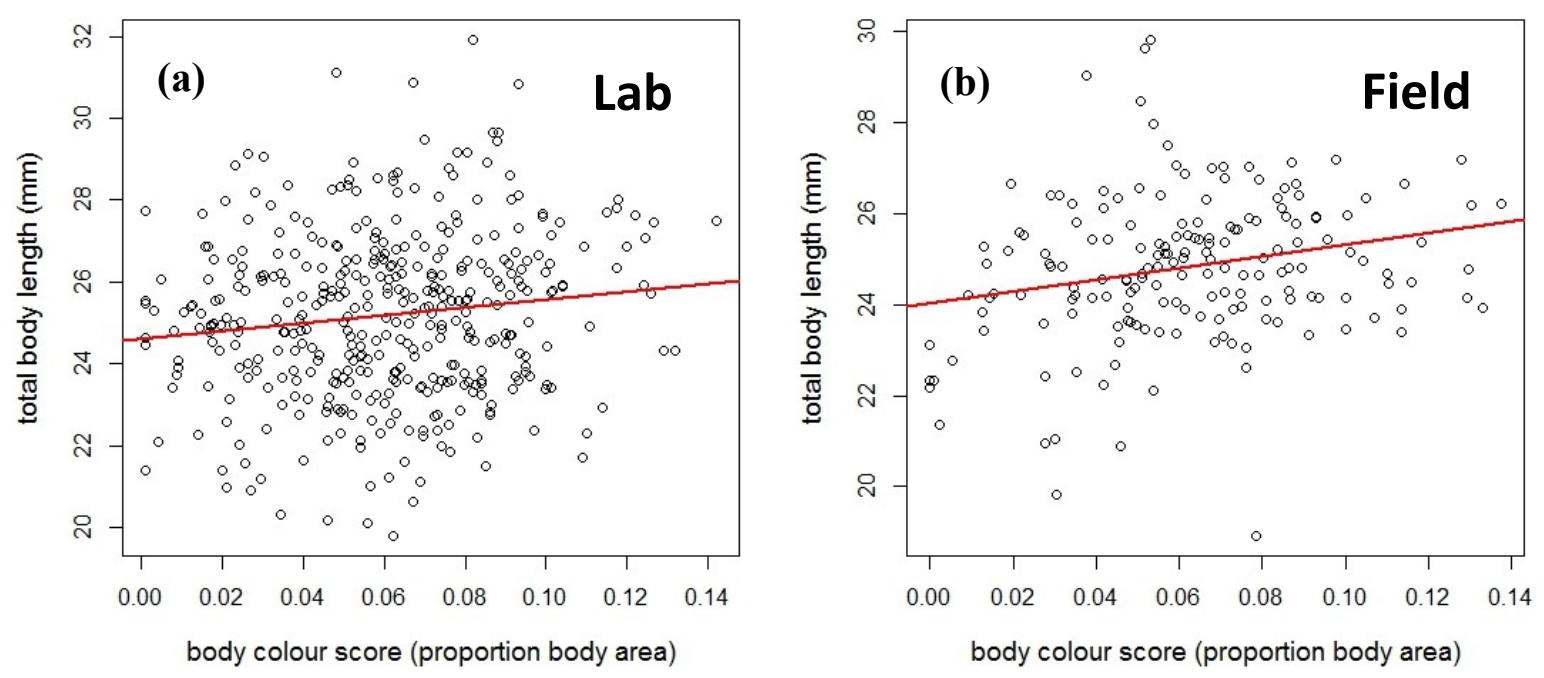

Figure 3. Relationship between the total body lengths $(\mathrm{mm})$ and colour scores (proportion of body area coloured orange and black) of Upper Aripo River male guppies (a) used in the dichotomous choice tests in the laboratory (Pearson's correlation coefficient: $\left.r=0.132, r^{2}=0.0174, p=0.0032, n=495\right)$ and $(b)$ in captured free-ranging mixed-sex shoals in the field $\left(r=0.239, r^{2}=0.057, p=0.00136, n=177\right)$. The lines-ofbest fit were obtained from linear regression analysis. 

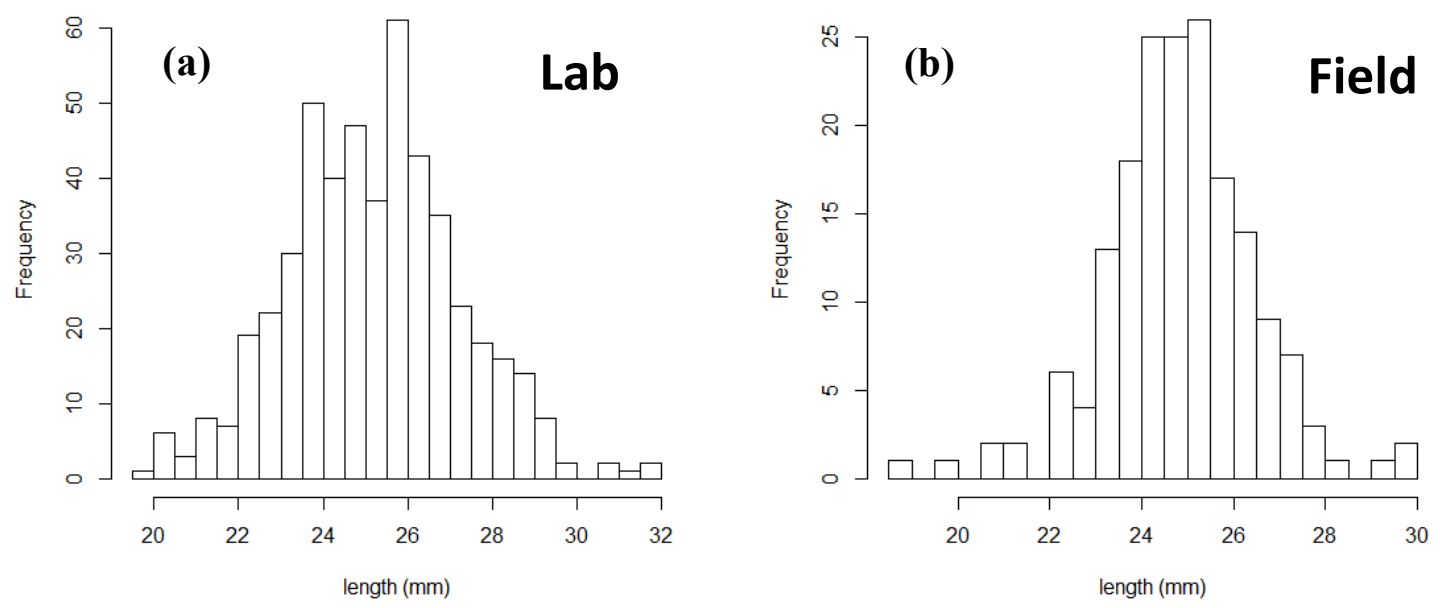

Figure 4. Frequency distribution of total body lengths of Upper Aripo River male guppies (a) used for the laboratory choice experiment $(n=495)$, and (b) in captured freeranging mixed-sex shoals in the field $(\mathrm{n}=177)$. 

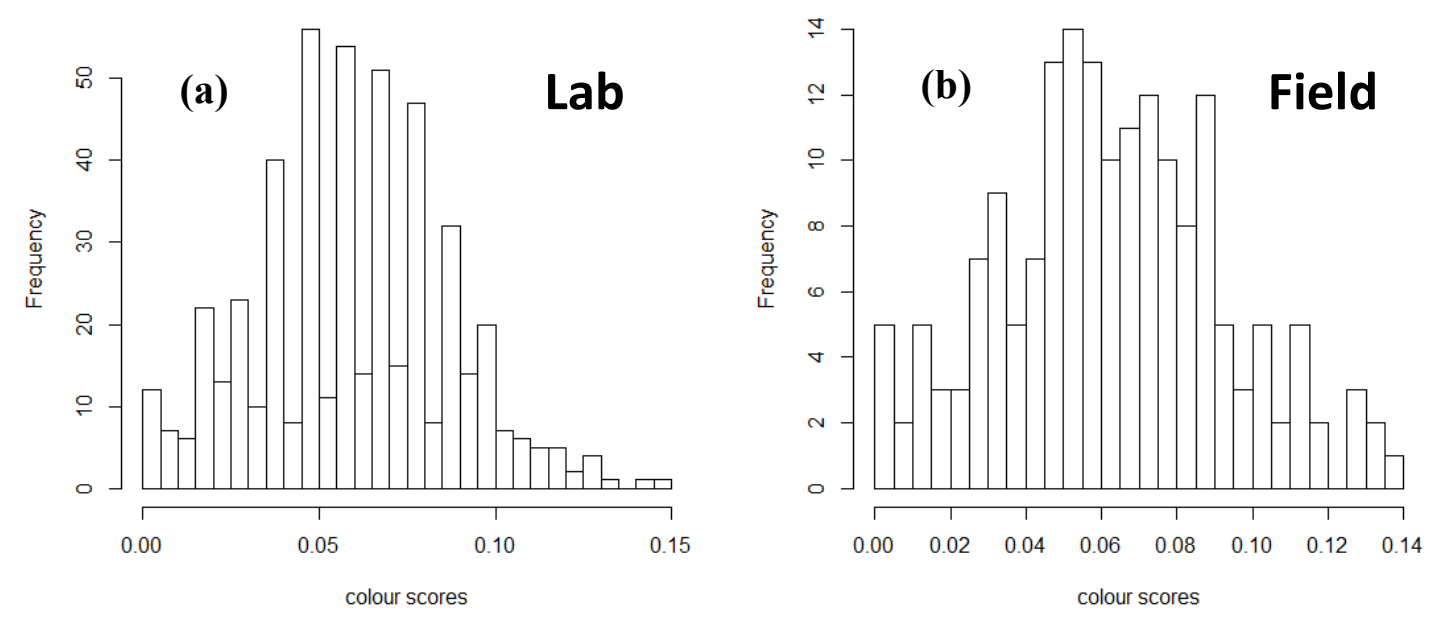

Figure 5. Frequency distribution of body colour scores (proportion of body area coloured orange and black) of Upper Aripo River male guppies (a) used for the laboratory choice experiment $(\mathrm{n}=495)$, and (b) in captured free-ranging mixed-sex shoals in the field ( $\mathrm{n}=177)$. 


\section{Part A: Testing for a shoal (social environment) preference in the}

\section{laboratory}

All focal males spent significantly more time in one of the two preference zones than the other, thereby exhibiting a non-random preference for one or the other mixed-sex stimulus shoals (paired t-test, $\mathrm{t}=17.41, \mathrm{df}=131, \mathrm{p}<0.001$, Fig. 6). Over all trials $(\mathrm{n}=$ 132), focal males spent significantly more time near the stimulus females than near the adjacent stimulus males whilst visiting either preference zones of the test aquarium (paired t-test, $\mathrm{t}=-4.15, \mathrm{df}=131, \mathrm{p}<0.001$; Fig. 7). Focal males were thus attentive to both females and adjacent rival male, but more so towards females than males, as expected if they were sexually motivated (to mate) and sensitive to potential sexual rivals nearby.

Given that the paired stimulus females were similar in body length (paired t-test, $\mathrm{t}=0.079, \mathrm{df}=262, \mathrm{p}=0.937)$ and thus unlikely to bias the group-association preferences of focal males, I tested for the potential effects of the phenotypes (body length and colour) of the focal male and the two rival stimulus males on the focal male's association time with the preferred mixed-sex stimulus shoal, whilst controlling for the body length of the stimulus females as co-variables. I essentially compared two alternative hypotheses using competing multiple regression models. 


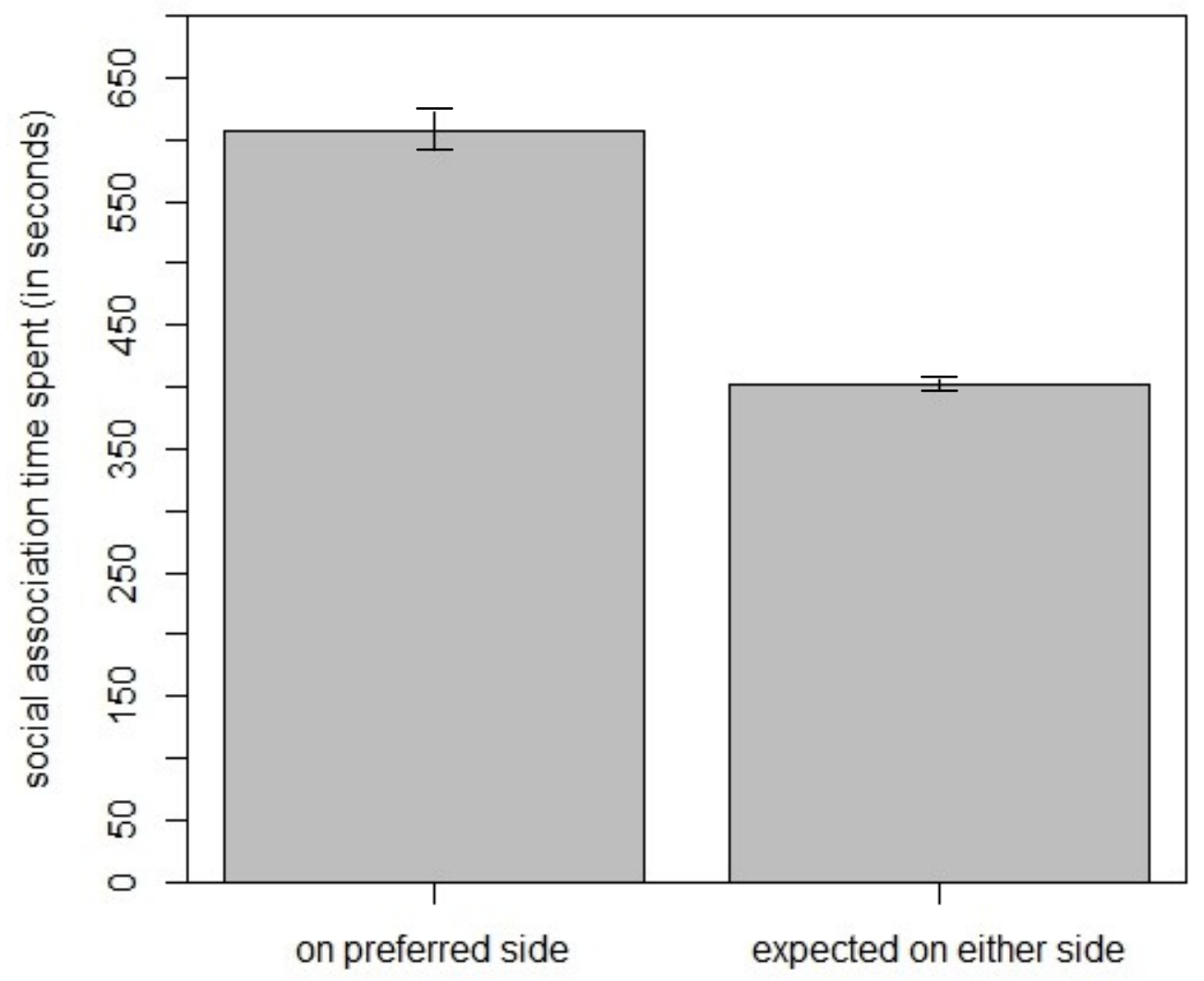

Figure 6. Mean $( \pm$ SE) time (in seconds) that the focal males $(n=132)$ spent on the side of the test aquarium with the preferred mixed-sex shoal (representing more than $50 \%$ of the focal male's total association time spent on either side), and time that he was expected to spend with either mixed-sex shoal based on chance (i.e. expected $50 \%$ of time spent on both sides). Paired t-test on absolute association times: $t=17.41$, $d f=131, p<0.001$. 


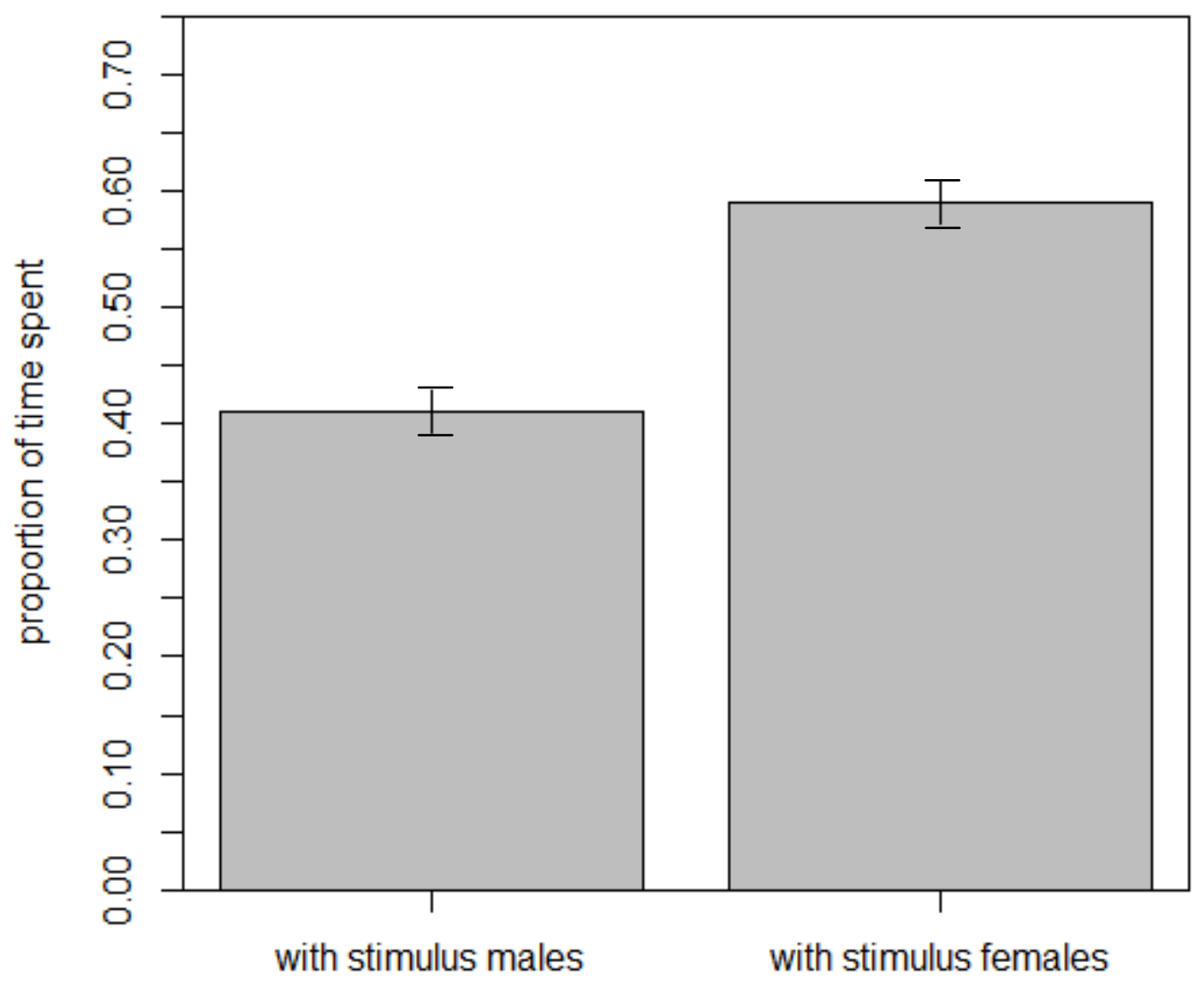

Figure 7. Mean $( \pm \mathrm{SE})$ proportion of time that focal males $(n=132)$ spent associating with either the stimulus female or the adjacent stimulus male in the paired mixed-sex shoals. Paired t-test on absolute association times: $\mathrm{t}=-4.15, \mathrm{df}=131, \mathrm{p}<0.001$. 
One hypothesis (coined here as the 'absolute phenotype' hypothesis) considered the absolute colour scores and body lengths of the two stimulus males and the focal male as explanatory (independent) variables for the observed association time that focal males spent with their preferred shoal. The second hypothesis (coined the 'relative phenotype' hypothesis) considered the differences in colour scores and body lengths between the two stimulus males and between each of them and the focal male as explanatory variables for the observed association time that focal males spent with their preferred shoal.

A test of the first ('absolute phenotype') hypothesis using a multiple regression model (Table 1) revealed that only the absolute body colouration scores of both the focal male $(p=0.006)$ and the rival stimulus male in the shoal that was not preferred $(p=0.025)$ significantly and positively affected the time the focal male spent associating with the other (preferred) mixed-sex shoal. This result suggests that the more colourful the focal males and the non-preferred rival males were, the greater was the focal males' association time with their preferred shoal and the greater their apparent avoidance of the other shoal that included a more colourful rival male. 
Table 1. Results of a multiple regression (following reduction using the Aikaike Information Criterion (AIC)) testing for the effects of absolute body length and colour score values of each male ('absolute hypothesis') on the time that focal males spent associating with their preferred mixed-sex stimulus shoal. Shown are the final model equation and the model's parameters, estimates, p-values for each coefficient, multiple Rsquared and adjusted R-squared, and p-value.

\begin{tabular}{|c|c|c|}
\hline \multicolumn{3}{|c|}{$\begin{array}{l}\text { Model: } \operatorname{lm}(\text { sqrt(timePside)) } \\
\text { focallength+focalcolour+NPstimlength+NPstimcolour+Pstimlength+ } \\
\text { Pstimcolour+focalcolour*Pstimcolour+focalcolour*NPstimcolour+lengthfemaleP) }\end{array}$} \\
\hline coeffecients & estimate & p-value \\
\hline (Intercept) & 17.690 & $0.003 *$ \\
\hline Focallength & 0.017 & 0.431 \\
\hline Focalcolour & 97.089 & $0.006^{*}$ \\
\hline NPstimlength & -0.047 & 0.761 \\
\hline NPstimcolour & 52.760 & $0.025^{*}$ \\
\hline Pstimlength & -0.258 & 0.126 \\
\hline Pstimcolour & 37.361 & 0.193 \\
\hline lengthfemaleP & 0.113 & 0.099 \\
\hline Focalcolour:Pstimcolour & -627.086 & 0.103 \\
\hline Focalcolour:NPstimcolour & -730.919 & $0.043 *$ \\
\hline \multirow[t]{2}{*}{ Multiple R-squared: 0.1048} & & uared: $\mathbf{0 . 0 3 8 8}$ \\
\hline & & p-valu \\
\hline \multicolumn{3}{|c|}{$\begin{array}{l}\text { Notes: sqrt }=\text { square root; timePside }=\text { absolute time spent on preferred side (i.e. with the } \\
\text { preferred shoal); focallength=length of focal male; focalcolour }=\text { colour score of focal male; } \\
\text { NPstimlength=length of non-preferred stimulus male; NPstimcolour=colour score of non- } \\
\text { preferred stimulus male; Pstimlength=length of preferred stimulus male; Pstimcolour=colour } \\
\text { score of preferred stimulus male; lengthfemaleP=length of female on preferred side; } \\
\text { focalcolour:Pstimcolour=interaction between colour of focal and preferred stimulus male; } \\
\text { focalcolour:NPstimcolour=interaction between colour of focal and non-preferred stimulus } \\
\text { male.* indicates significance of coffecient }(\mathrm{p} \leq 0.05) \text {. }\end{array}$} \\
\hline
\end{tabular}


Given this result, I then tested the alternative 'relative phenotype' hypothesis using a different multiple regression model (Appendix Table A1) that included as explanatory variables not only the relative phenotypic traits (colour and length) of the stimulus males and focal male, but also the absolute body colour scores of the focal male and the stimulus males (as they were significant in the first above-mentioned model, Table 1). Following AIC model selection, the most parsimonious explanatory model (model \# M11 in Appendix Tables A1 and A2) included the differences in both the body colouration and body length between the focal male and the rival male in the preferred mixed-sex shoal, and their interaction, whilst controlling for the body length of the stimulus female in the other (non-preferred) shoal. This final model revealed a significant negative effect of the difference in colour $(\mathrm{p}=0.0121)$, and a marginally non-significant negative effect of the difference in body length $(p=0.076)$, between the focal male and the rival male in the preferred shoal on the association time of the focal male with the preferred shoal (Table 2). Of these two alternative competing models/hypotheses, the latter 'relative phenotype' model/hypothesis best explains the preference behaviour of the focal males (Table 2; Appendix Table A3). 
Table 2. Results for the most parsimonious (best-fit), multiple regression model according to AICc (Model "M11" in Table A2) testing for the effects of the body length and colour differences between focal male and preferred stimulus male on the time that focal males spent associating with their preferred mixed-sex stimulus shoal. Shown are the final model equation and the model's parameters, estimates, $\mathrm{p}$-values for each coefficient, multiple R-squared and adjusted R-squared, and p-value.

\begin{tabular}{|c|c|c|}
\hline \multicolumn{3}{|c|}{ Model: $\operatorname{lm}($ sqrt(timePside) $) \sim$ Pdifflength $x$ Pdiffcolour + (1|focalID) + lengthfemaleNP } \\
\hline coeffecients & Estimate & p-value \\
\hline Pdifflength & -6.305 & 0.076 \\
\hline Pdiffcolour & -0.958 & $0.0121 *$ \\
\hline lengthfemaleNP & 0.109 & 0.101 \\
\hline Pdifflength: Pdiffcolour & 2.669 & 0.436 \\
\hline \multirow{2}{*}{ Multiple R-squared: 0.0856} & \multicolumn{2}{|c|}{ Adjusted R-squared: 0.0568} \\
\hline & & p-value: 0.0219 * \\
\hline \multicolumn{3}{|r|}{$\begin{array}{l}\text { referred side; Pdifflength }= \\
\text { in relation to focal male; } \\
\text { ulus male in relation to focal } \\
\text { variable; lengthfemaleNP = } \\
\text { : Pdiffcolour = interaction of } \\
* \text { indicates significance of }\end{array}$} \\
\hline
\end{tabular}


To validate if the final reduced 'relative phenotype' model is the qualitatively best one to describe the preferences of the focal males, the latter model was compared posthoc to a model that included only the absolute colour scores and body length values of the two stimulus males (see Appendix Table A2). This comparison showed that the absolute colour scores and body length of the stimulus males remained unimportant in explaining focal male association times (Appendix Table A3), and confirmed that it is indeed the relative differences in phenotypic traits between the focal male and the rival male in the preferred shoal that best explains the association time spent by the focal male with the preferred shoal.

In summary, the results of my laboratory-based dichotomous choice experiment indicate that overall Upper Aripo male guppies preferred to associate with a mixed-sex group that contained a rival male that was less attractive sexually (less colourful and smaller) than themselves, when given a choice between two mixed-sex shoals (Table 2, Figs. 8 and 9). Notwithstanding this finding, the most parsimonious model (Table 2) explained only about $6 \%$ of the observed variation in focal male association time with the preferred shoal (adjusted R-squared $=0.0568, \mathrm{p}=0.0219$ ); therefore, a considerable portion of this behavioural variation remains unaccounted for and likely reflects the complexity of the behavioural decisions that male guppies have to make when choosing which mixed-sex shoals to join in pursuit of mating opportunities. 


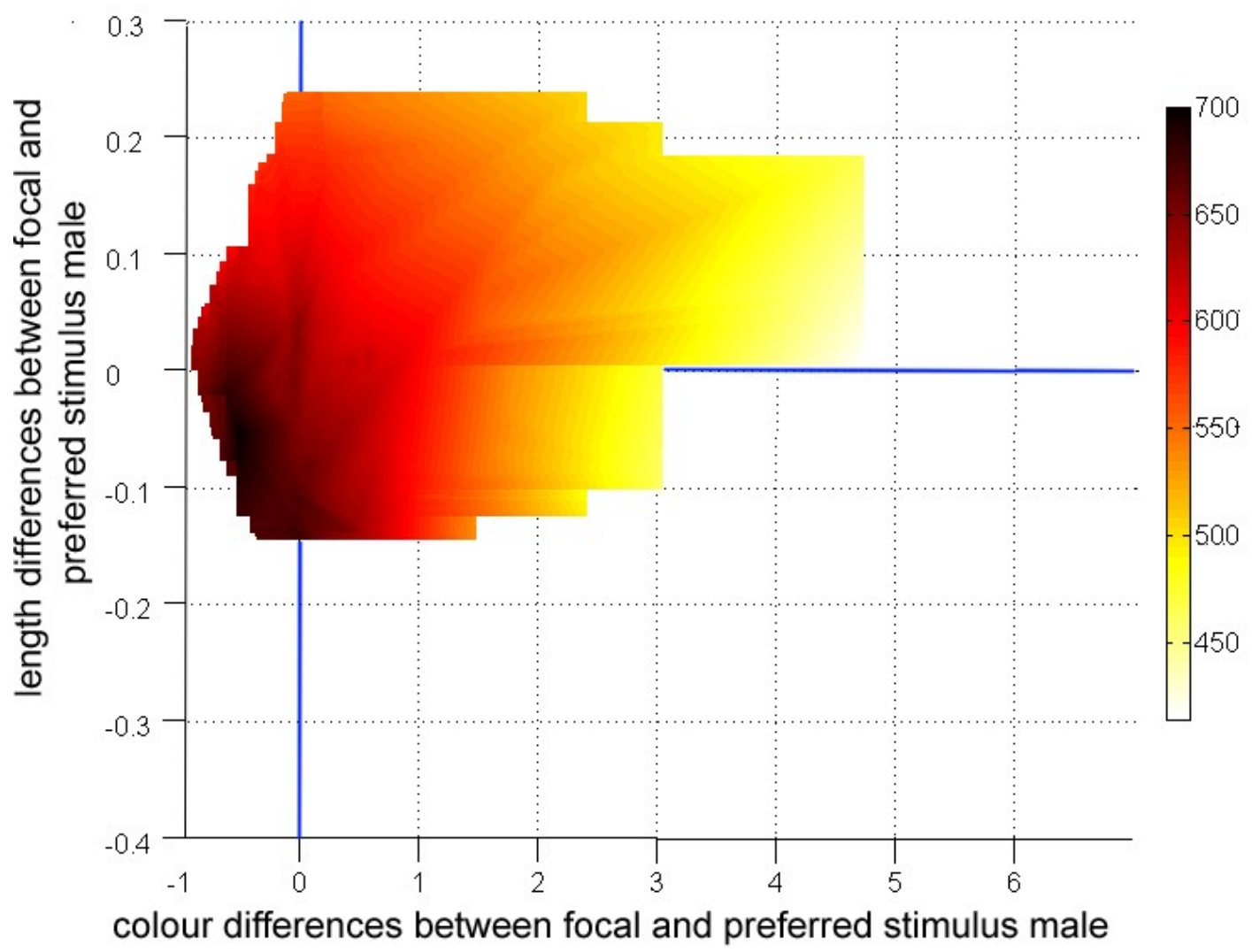

Figure 8. Two-dimensional heat diagram depicting the model-fitted association times (in seconds) spent by focal males near their preferred shoal in relation to the differences in body colouration (x-axis) and body length (y-axis) between the focal male and stimulus male in the former's preferred mixed-sex shoal. On the $\mathrm{x}$-axis, the colour difference between focal and preferred stimulus male was plotted as a proportion of the focal male's colour score. The y-axis shows the body length difference between focal and preferred stimulus male as a proportion of the focal male's body length. The colour (heat) scale on the right denotes the dependent variable (association time of focal males), ranging from $400 \mathrm{~s}$ (white colour) to a maximum of $700 \mathrm{~s}$ (deep red). The blue lines represent the location of 0 on the $\mathrm{x}$ and $\mathrm{y}$ axes. 


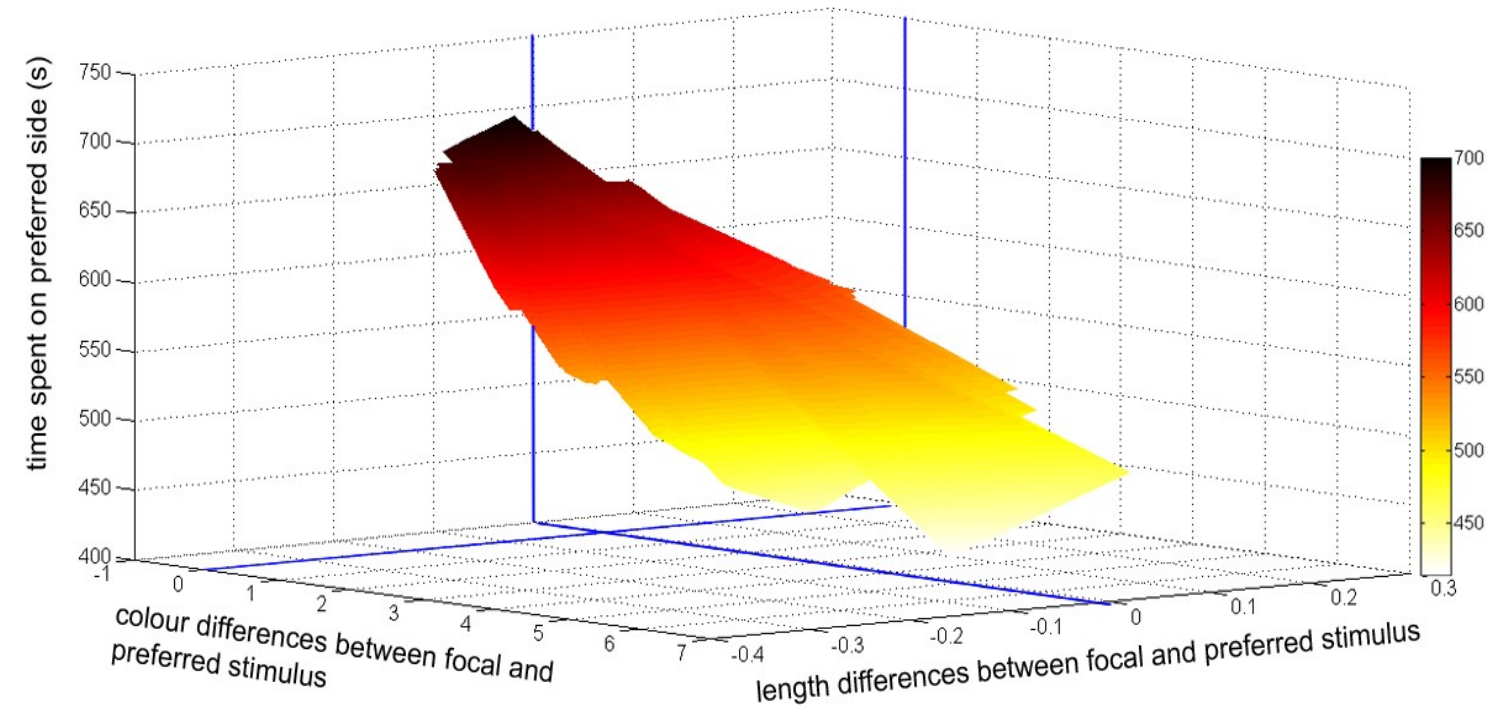

Figure 9. Three-dimensional heat diagram depicting the model-fitted association times (in seconds, y-axis) spent by focal males near their preferred shoal in relation to the differences in body colouration (x-axis) and body length (z-axis) between the focal male and stimulus male in the former's preferred mixed-sex shoal. On the x-axis, the colour difference between focal and preferred stimulus male was plotted as a proportion of the focal male's colour score. The z-axis shows the body length difference between focal and preferred stimulus male as a proportion of the focal male's body length. The colour (heat) scale on the right denotes the dependent variable (association time of focal males), ranging from $400 \mathrm{~s}$ (white colour) to a maximum of $700 \mathrm{~s}$ (deep red). The blue lines represent the location of 0 on the $\mathrm{x}, \mathrm{y}$ and $\mathrm{z}$ axes. This diagram shows the same results as in Figure 8, but in three dimensions rather than two dimensions. 


\section{Part B: Testing for social associations among male guppies in the wild}

A total of 67 mixed-sex guppy shoals, containing a total of 177 male guppies, were collected intact in six different pools in the Upper Aripo River. On average ( \pm SE), the shoals comprised $5.53 \pm 0.40$ fish (range $=3-19$ ), of which $2.63 \pm 0.12$ were males (range $=2-6)$ and $2.90 \pm 0.35$ females (range $=1-15)$. The proportion of males in these mixed-sex shoals declined with increasing shoal membership size $(r=-0.698$, $\mathrm{p}<0.001$; Appendix Fig. 2A).

Contrary to the expectation of phenotypic assortment based on the results of the laboratory dichotomous choice test (Part A), male guppies were not assorted by either total body length or body colouration in the free-ranging mixed-sex shoals that were collected in the Upper Aripo River. Within-group variability in male body length (oneway ANOVA, $\left.\mathrm{F}_{(66,110)}=1.15, \mathrm{p}=0.26\right)$ and body colouration $\left(\mathrm{F}_{(66,110)}=0.97, \mathrm{p}=0.54\right)$ did not differ from their respective between-group variability. Consequently, neither the above F-statistic value for body length or body colouration fell within the top or bottom 2.5 percentiles of the F-distribution (Figs. 10 and 12) or the distribution of the 10,000 randomly generated F-values (Figs. 11 and 13), indicating that there was neither negative or positive assortment, but rather random assortment, of males based on their phenotypes within shoals in the wild. 


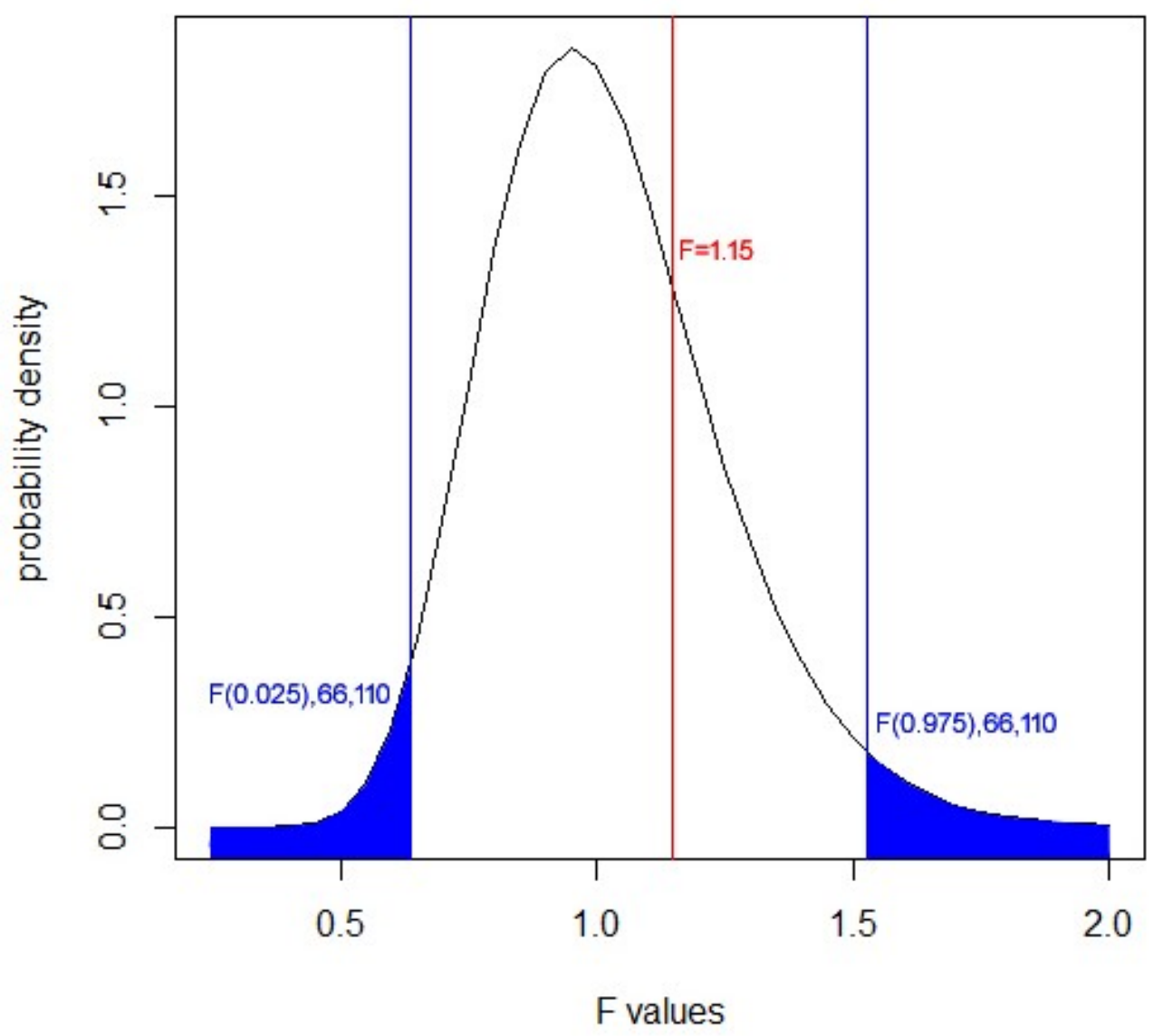

Figure 10. Probability density function of the theoretical F-distribution, with numerator $\mathrm{df}=66$ and denominator $\mathrm{df}=110$. The critical F-values for the lower $2.5^{\text {th }}$ percentile and upper $2.5^{\text {th }}$ percentile for a two-tailed test of the null hypothesis are shown in blue colour. The red vertical line indicates the actual calculated F-value obtained from an ANOVA comparing the within-group to between-group variation in the body length of male guppies present in free-ranging mixed-sex shoals $(n=67)$ that were collected in the Upper Aripo River, Trinidad. 


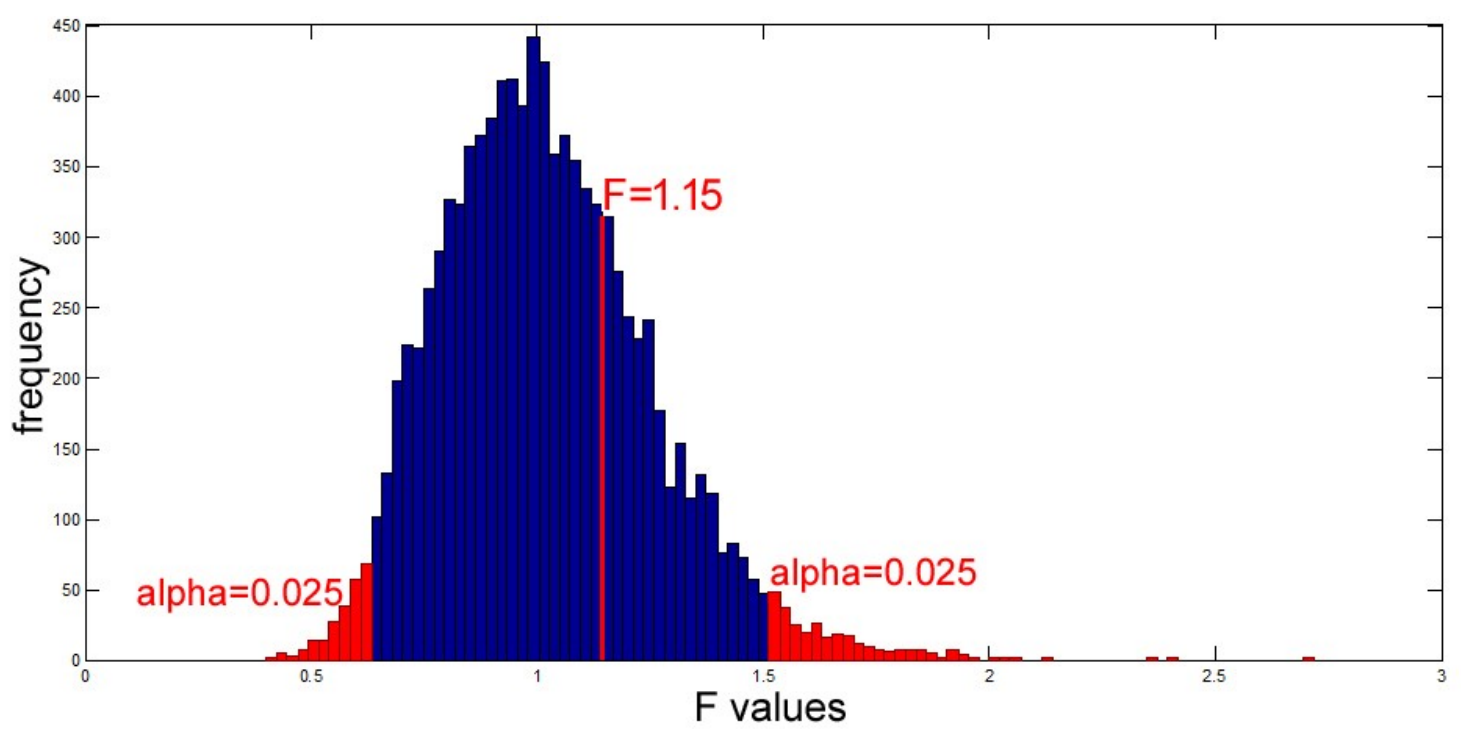

Figure 11. Frequency distribution of F-values obtained from ANOVAs comparing the within-group to between-group variation in the body length of Upper Aripo River male guppies in 10,000 randomly simulated mixed-sex groups, as described in the Methods. The red vertical line indicates the actual calculated F-value obtained from an ANOVA comparing the within-group to between-group variation in the body length of male guppies present in free-ranging mixed-sex shoals $(n=67)$ that were collected in the Upper Aripo River, Trinidad. The red areas represent the lower and upper $2.5^{\text {th }}$ percentiles of the frequency distributions of the F-values for the 10,000 simulated groups. 


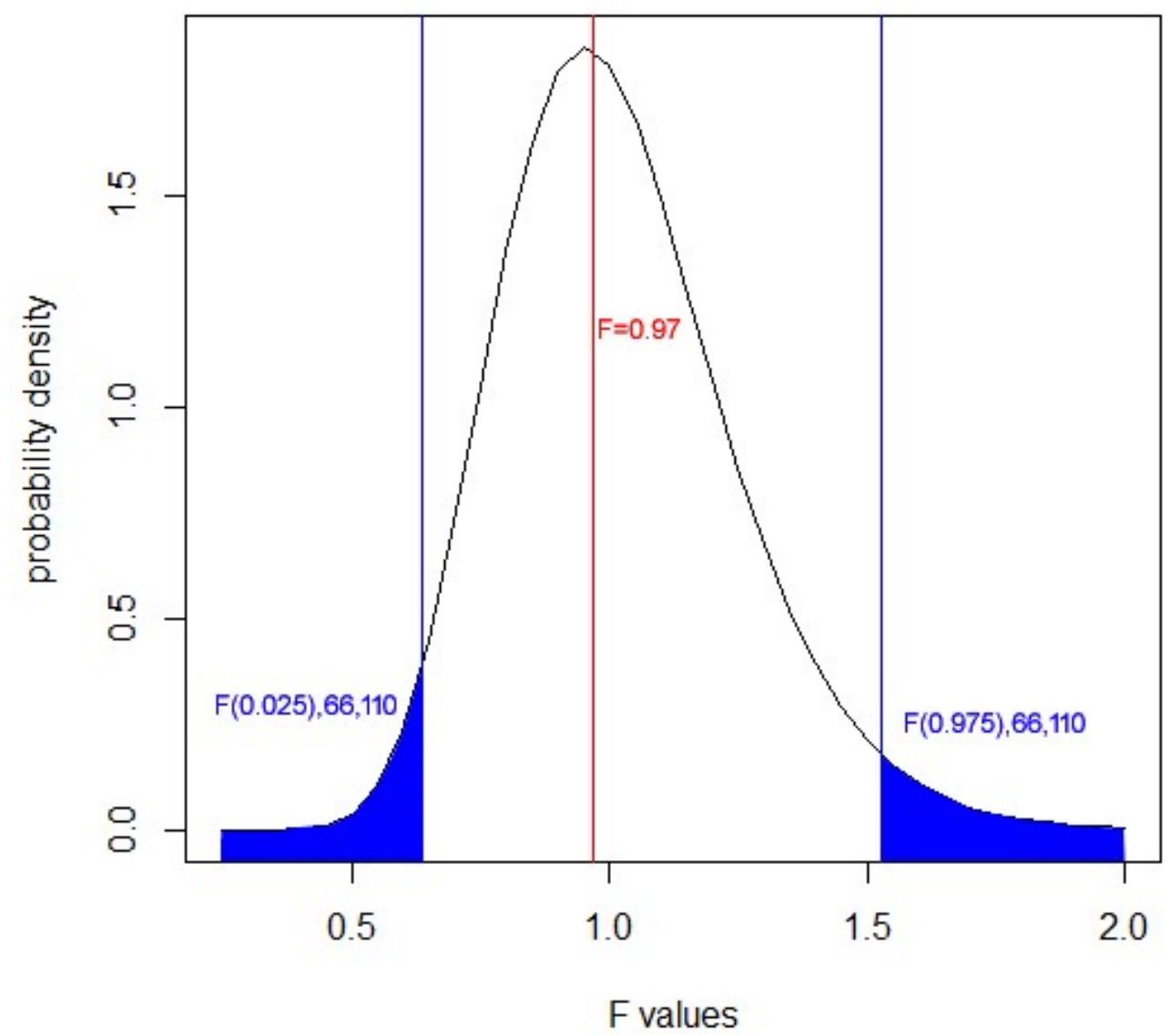

Figure 12. Probability density function of the theoretical F-distribution, with numerator $\mathrm{df}=66$ and denominator $\mathrm{df}=110$. The critical F-values for the lower $2.5^{\text {th }}$ percentile and upper $2.5^{\text {th }}$ percentile for a two-tailed test of the null hypothesis are shown in blue colour. The red vertical line indicates the actual calculated F-value obtained from an ANOVA comparing the within-group to between-group variation in the body colouration of male guppies present in free-ranging mixed-sex shoals $(n=67)$ that were collected in the Upper Aripo River, Trinidad. 


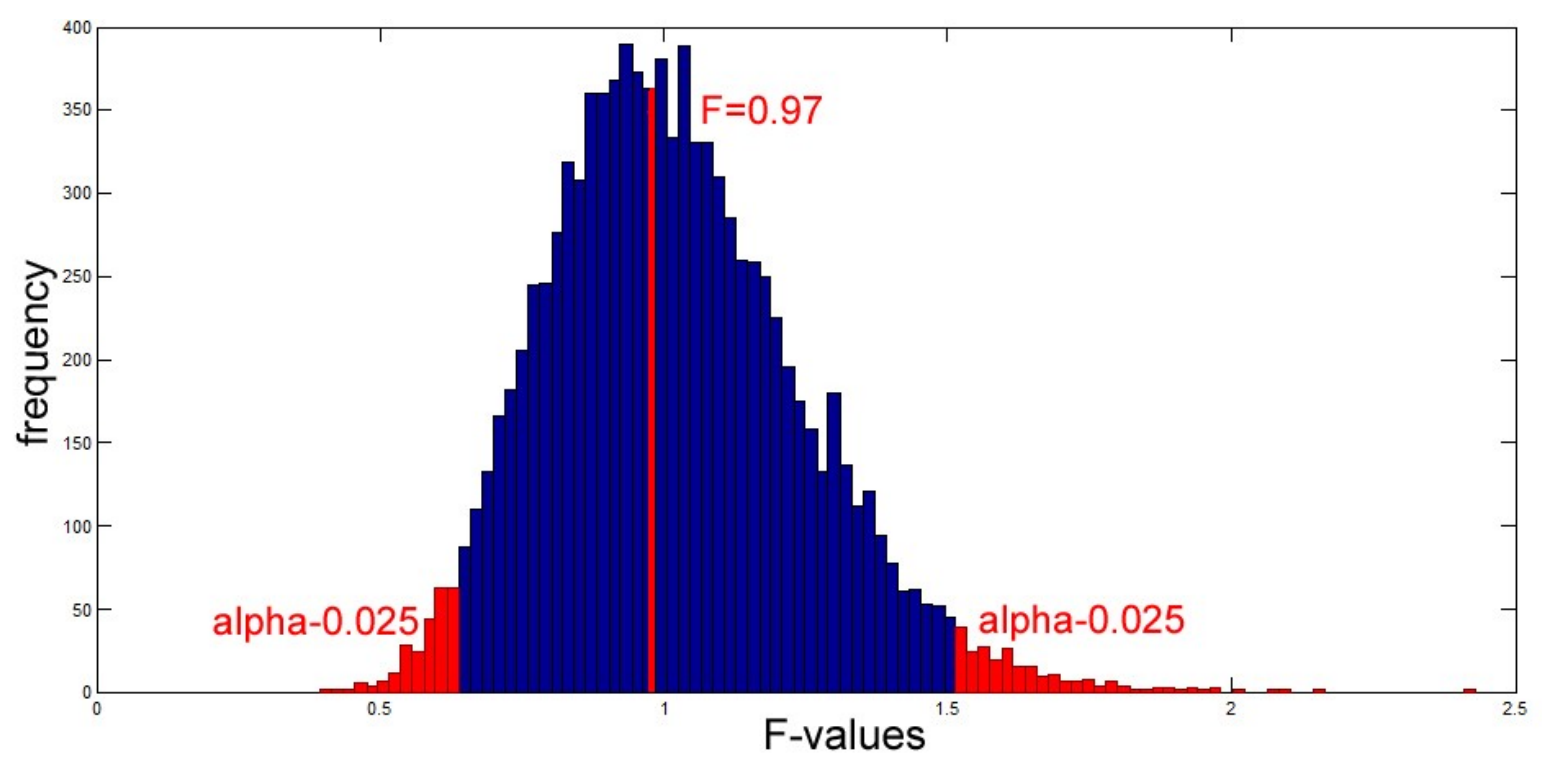

Figure 13. Frequency distribution of F-values obtained from ANOVAs comparing the within-group to between-group variation in the body colouration of Upper Aripo River male guppies in 10,000 randomly simulated mixed-sex groups, as described in the Methods. The red vertical line indicates the actual calculated F-value obtained from an ANOVA comparing the within-group to between-group variation in the body colouration of male guppies present in free-ranging mixed-sex shoals $(n=67)$ that were collected in the Upper Aripo River, Trinidad. The red areas represent the lower and upper $2.5^{\text {th }}$ percentiles of the frequency distributions of the F-values for the 10,000 simulated groups. 


\section{DISCUSSION}

Mate choice is a form of sexual selection in which the choice of mates depends on the attractiveness of their secondary sexual traits. These traits may indicate the reproductive quality of the bearer and can have implications for the overall fitness of an individual (Andersson, 1994). The mating behaviour of individuals may vary temporarily and spatially (Jennions and Petrie, 1997) and can be influenced by their social and ecological environment (Valone and Templeton, 2002). In social species, surrounding conspecifics can alter the mating preferences and mate choices of individuals (Westneat et al., 2000; Valone and Templeton, 2002). If decisions to mate with particular individuals depend on the attractiveness of their traits, then it is interesting to know if these characteristics are evaluated by members of the opposite sex by using absolute trait values (threshold criteria) or if they are assessed relative to surrounding phenotypes. If

the latter is true, then individuals can be expected to actively choose a social environment in which they appear relatively more attractive to the other sex in that social environment (Oh and Badyaev, 2010).

\section{Social associations among male rival guppies in a dichotomous choice test}

In the dichotomous choice experiment of the current study, focal male Trinidadian guppies preferred to associate with a mixed-sex shoal that comprised a female in proximity to a male sexual rival who was less ornamented and smaller than themselves over another shoal consisting of a female and a more ornamented and larger rival male 
sexual rival. When both the absolute and relative phenotypic traits (body length and colouration) of the stimulus males and focal male were included in multiple regression models, only the differences in body colouration and length between the focal and preferred stimulus males explained a significant proportion of the observed variation in the time the focal male spent associating with the preferred mixed-sex stimulus group (i.e. stimulus female near a smaller and less colourful rival male). Male guppies therefore actively chose to associate with a social group in which they appear relatively more sexually attractive (more colourful and larger) to females. It would thus appear that male guppies take their own phenotype and that of their sexual rivals into account when making decisions regarding which mixed-sex social groups to join in pursuit of mating opportunities, at least when given a dichotomous choice in the laboratory.

The above finding is similar to that of Oh and Badyaev (2010), who found that less attractive (dull) male house finches actively selected social groups in which they were the relatively more attractive males in order to increase their mating success. The result of my dichotomous choice experiment also corroborates the recent study of Gasparini et al. (2013), who reported that male guppies (originating from a highpredation population in Trinidad) maximized their relative attractiveness in a sexual context by preferentially associating with the less colourful of two male conspecifics when given a dichotomous choice. They ruled out the possibility of male-male aggression being the cause of this preferential association. If male-male competition is strong, then males might avoid females surrounded by rivals that are better competitors than themselves; moreover, if orange colour is an indicator of high male aggression, then colourful males should be avoided by rival males (Fawcett and Johnstone, 2003). 
However, Gasparini et al. (2013) showed that the body colouration (carotenoid, melanin and iridescent colouration) and body size of male guppies were not related to their aggressive behaviour in the presence of females. Male-male competition with direct threats and combat is rare and does not determine male mating success in the guppy (Houde, 1988). On the other hand, scramble or interference competition for access to females - another form of intrasexual selection - is known to occur in male guppies. It usually does not involve aggression between the males. Male guppies sometimes interrupt other males' courtship when they jockey for position in front of females (Houde, 1997). It is possible that body size and even colouration may play a role in the success of interference, but this remains unknown.

Moreover, in the study by Gasparini et al. (2013), male guppies did not show a social association preference for either stimulus male in the absence of females. Therefore, male preferential social assortment is most likely driven by sexual attractiveness than male-male competition. Additionally, Gasparini et al. (2013) suggested that male preferential association with females that were surrounded by rival males of a certain phenotype can be influenced by prior experience. Male guppies chose females that had previously been seen with drabber males, but were no longer surrounded by competitors. They therefore proposed that a focal male's assessment of his own sexual attractiveness and that of his sexual rivals is acquired through experience (Gasparini et al., 2013). 
The results of my multiple regression analysis indicate that focal male guppies based their preference for a particular mixed-sex group mostly on the relative difference in phenotype between themselves and the rival stimulus male in that group. This is in accordance with the theory predicting that individuals assess the attractiveness of potential mates by comparing them to current alternative phenotypes rather than to a fixed threshold trait value, above which an individual is acceptable as a mate (Waite, 2001; Bateson and Healy, 2005). The sexual attractiveness of any given individual would therefore dependent on the relative attractiveness of nearby sexual competitors. Decision making based on comparing and assessing various traits amongst potential mates is cognitively easier than forming an independent absolute evaluation of each alternative phenotype present (Bateson and Healy, 2005). Therefore, previous experience and social context play important roles in behavioural decision making (Waite, 2001), suggesting that past encounters with mates influence mating decisions in the present. Additionally, if mating preferences depend on the context in which a male is evaluated, then males can benefit from adjusting their level of sexual signalling (e.g. courtship) according to the presence and behaviour of nearby rivals (Bateson and Healy, 2005), or, as suggested in the current study, by preferentially joining social groups in which they appear more sexually attractive and in which they may gain greater mating success than otherwise.

My laboratory-based results, combined with those of other recent studies (e.g. Oh and Badyaev, 2010; Gasparini et al., 2013; Jordan et al., 2014), provide evidence that males actively seek or create social environments with properties that may increase their relative sexual attractiveness to females and thus mating success. In the guppy, females generally prefer males with more orange colouration (Kodric-Brown, 1985; Long and 
Houde, 1989; Endler and Houde, 1995; Pilastro et al., 2004) and larger body size as mates (Reynolds and Gross, 1992; Watt et al., 2001; Herdman et al., 2004) and gain fitness benefits in doing so (e.g. Reynolds and Gross, 1992; Watt et al., 2001). Carotenoid colouration has furthermore been shown to be correlated with sperm quantity and quality in male guppies (e.g. Pitcher and Evans, 2001; Pitcher et al., 2007). Males with more orange colouration produce larger ejaculates that contain more motile and longer sperm compared with drabber males (Pilastro et al., 2004; Pitcher et al., 2007).

In addition to such pre-copulatory female mate choice, post-copulatory cryptic female mate choice also occurs in the guppy, which results in biased sperm use in favour of particular males and contributes to the evolution of male ornamentation (Pilastro et al., 2004). The number of sperm transferred by a male during copulation can depend on the female's perception of his relative attractiveness, as influenced by his courtship behaviour for example (Edvardsson and Göran, 2000). If a female's perception of a male's attractiveness can be manipulated socially, then males may benefit reproductively from preferentially associating with less colourful male social partners (Pitnick and Brown, 2000), as was the case for male guppies in the current study. Therefore, by joining a mixed-sex group in which he appears to be more attractive phenotypically than his nearby sexual rivals, a focal male would thereby increase his chances of being chosen as a preferred mate by the female(s) in the group (pre-copulatory sexual selection) and perhaps also experience greater fertilization success through post-copulatory sperm competition and female cryptic choice.

Although they possess a heritable component, body colouration and body length in male guppies are condition-dependent plastic traits and vary among populations (Houde, 
1997). For example, melanic colour spots are affected by stress and courtship intensity (Endler, 1991). The saturation and brightness of carotenoid colours in male guppies depend on food availability and parasite load (Kodric-Brown, 1989; Houde, 1992; Karino and Haijima, 2001). Similarly, female preference for orange colour is rather plastic and varies within and guppy populations (Endler and Houde, 1995; Houde and Hankes, 1997). Criteria for female choice are known to fluctuate within and between populations, depending on female age (Kodric-Brown and Nicoletto, 2001), water colour and predation risk (Endler and Houde, 1995; Godin and Briggs, 1996; Weese et al., 2010), for example. In most Trinidadian guppy populations, females prefer males with more orange colouration and larger bodies, if body length is important (Endler and Houde, 1995). However, in some populations, no strong female preference based on colouration exists (e.g. Weese et al., 2010). As mentioned above, if mating preferences depend on the context in which males are evaluated (Waite, 2001; Bateson and Healy, 2005), then the immediate social environment may also explain some of the observed variation in female mating preferences, based on male phenotypic traits, that have been found in different populations of the Trinidadian guppy (refs loc. cited).

Although female mate choice based on male ornamentation is widely studied (Andersson, 1994; Houde, 1997), there are other factors contributing to preferential mating in guppies and which could therefore influence male-male social associations. Neither of the following has been controlled for in the current study, but nonetheless have to be taken into account and discussed here. Negative frequency-dependent selection (NFDS) suggests that particular genotypes in a population are favoured when they are relative rare (Ayala, 1974). According to the rare-male hypothesis and NFDS, males that 
have an uncommon colour pattern within a population experience higher reproductive fitness than those with more common colour phenotypes by mating with more females and siring more offspring (Hughes et al., 2013). In the Trinidadian guppy, females are more likely to mate with males that are unfamiliar to them than with familiar ones (Hughes et al., 1999). Males could thus potentially benefit from associating with rival males that have a more common but different phenotype than themselves and which are thus likely more familiar (and less preferred) to females.

When considering social associations based on body colouration in poecilid fishes, we assume that fish have a similar colour perception to that of humans. This is not so. Guppies are capable of perceiving wavelengths outside of the human visual spectrum, and have a potential for tetrachromatic colour vision. They therefore have the capacity to perceive UV wavelengths (Archer et al., 1987; Thorpe et al., 1993). Some studies (e.g. Kodric-Brown and Johnson, 2002; White et al., 2003) suggest that female guppies take the UV reflection of male body colouration patterns into account when choosing mates. The structural (iridescent purple/blue, white and green) and pigment (orange) colour patches of male guppies reflect UV light, and males differ in the amount of UV light that is reflected from their body colours (White et al., 2003). The importance of UV reflection in female guppy mate choice, however, remains uncertain and controversial (KodricBrown and Johnson, 2002; Smith et al., 2002; White et al., 2003).

\section{Social associations among male guppies in free-ranging shoals}


Given that my laboratory dichotomous choice experiment showed a significant preferential association of focal males with females that were surrounded by phenotypically less attractive males (i.e. less colourful and smaller) than themselves, I expected to find a negative assortment of male guppies based on body length and colouration in free-ranging shoals in the wild. If an individual male always chooses to associate with other males of a different phenotype than itself, then males in any one group should be all significantly different phenotypically from each other than expected by chance. However, contrary to expectation, male guppies occurring in mixed-sex shoals in the Upper Aripo River were not assorted by either body colour or body length. I consider below plausible, non-mutually exclusive explanations for this finding.

First, if all males seek a social environment in which they are the relatively more attractive individual phenotypically, then this would likely result in unstable group composition because a focal individual male would opt to leave a current group in search of another group (in which he could be the more attractive male) if he perceives that is relative sexual attractiveness has decreased as a result of another, more attractive male having joined that group. This plausible scenario could be explored theoretically using simulations, as well as by following individually-marked fish in the wild and recording their behaviour in real time, in the future.

Second, guppies live in fission-fusion societies in which group memberships change continually (Croft et al., 2004); these fish swim about constantly and join and leave groups frequently. Nonetheless, female guppies (more so than males) form smallworld social networks in the wild in which some relatively stable social associations among individuals (most commonly pairs) occur (Croft et al., 2004, 2012). The 
movement of individual animals within and among social groups is often related to their mating system and movement patterns commonly vary between the sexes (Croft et al., 2003b; Ruckstuhl and Neuhaus, 2005). In general, males are mostly pre-occupied with searching for receptive females (Andersson, 1994; Houde, 1997). Male guppies move more within and between pools than females, changing groups every few seconds (Croft et al., 2003a, 2003b). Such movements increase a male's likelihood of encountering unfamiliar and novel females, who may be more receptive to their mating attempts than familiar females (Hughes et al., 1999; Kelley et al., 1999). This is supported by the fact that the tendency of males to emigrate from their current shoal increases as the sex ratio becomes more male-biased, so as to minimize their sperm competition risk and intensity from increasing numbers of rival males (Croft et al., 2003b). Consequently, such high levels of mate-searching activity and inter-group movement among male guppies in the wild explains, at least partially, the observed lack of male-male social associations based on phenotype (body colouration and length) in wild Upper Aripo River guppies in the current study, despite my laboratory finding of a preference for associating with relatively less attractive rivals in males from this population.

Third, sexual conflict could also contribute to unstable group composition and random assortment by phenotype in guppies in the wild. Whereas males spent the majority of their time searching for and sexually pursuing females for mating opportunities, females spent considerable effort at avoiding unwanted male sexual harassment (e.g. Magurran and Seghers, 1994). Male harassment is potentially costly for females and can reduce their condition and reproductive success (Ojanguren and Magurran, 2007). Male harassment, and resultant female avoidance behaviour, can 
consequently disrupt female social associations and network structures (Darden et al., 2009), and potentially renders stable phenotype-dependent social associations among males less likely to occur.

Fourth, the observed lack of phenotype-dependent social associations among wild male guppies in the Upper Aripo River population might be an artifact of my field sampling method. By visually scanning pools within this river, I collected by seining focal mixed-sex groups of guppies that were located visually. This 'gambit-of-the-group' (Croft et al., 2008) method of sampling represents a single 'snap-shot' of a social group at the time of collection/observation and assumes that the individuals that were present in the group at the time of collection were together in that same group for some (unknown) amount of time in the immediate past. This assumption is not realistic for the guppy given the highly dynamic fission-fusion nature of their society (Croft et al., 2004), the frequent movements of fish (males in particular) in and out of groups (Croft et al., 2003a, 2003b), and the fact that it commonly takes several days for social familiarity to develop in the guppy (Griffiths and Magurran, 1997a).

Lastly, although highly dynamic, shoaling in fishes is known to be non-random (Krause and Ruxton, 2002). The tendency to shoal is higher in habitats with a high predation risk (Magurran et al., 1994). Shoaling based on similar phenotypes is associated with an anti-predator benefits (Krause and Ruxton, 2002). Known as the confusion effect, it is more difficult for predators to single out and catch one particular prey amongst many when attacking a homogenous-looking group (Krause and Ruxton, 2002). The presence of an odd individual, on the other hand, increases its likelihood to be singled out and captured by predators (oddity effect) (Landeau and Terborgh, 1986). 
Assortment by phenotype should therefore be greater under increasing predation risk (Croft et al., 2009a). The lack of phenotype-dependent assortative grouping in male guppies in the Upper Aripo River observed in the current study may be partly owing to the absence of major piscivorous predators on adult guppies, and thus predator-driven selection for assortative shoaling, in this population.

Other criteria (than body colour and body size) for social group assortment include personality, sex, familiarity and relatedness (e.g. Magurran et al., 1994; Croft et al., 2012; Wilson et al., 2013). Some studies have found a link between social behaviour, population structure and personality (Krause et al., 2010; Aplin et al., 2013). Personality traits or behavioural syndromes - defined as the within-individual and betweenindividual consistency in behaviour across contexts (Sih et al., 2004) - can define social networks and, vice versa, network structures can influence individual personalities (Krause et al., 2010; Webster and Ward, 2011). In wild songbirds, for example, fastexploring individuals move more between groups and form less stable associations than slow-exploring ones, which leads to a non-random distribution of males across groups (Aplin et al., 2013). Similarly, in sticklebacks, bolder fish have more social connections than shy fish, which form fewer but longer relationships (Pike et al., 2008). Croft et al. (2009) observed that personality also played a role in the social fine structure of guppy shoals in the wild. Behavioural traits such as predator inspection and shoaling tendency are consistent over time and differ between individuals (Budaev, 1997; Croft et al., 2009b). For example, individuals with a similar predator inspection tendency are thought to more likely engage in predator inspection behaviour together and, through this pathway, maintain cooperation in the population (Croft et al., 2009b). However, 
behavioural assortment in shoals has been alternatively hypothesized to arise from passive mechanisms rather than active partner preferences (Croft et al., 2009b).

Relatedness is another factor by which individuals may assort themselves in a group. Associating with kin can enhance the general advantages of grouping since it yields indirect fitness benefits (Hamilton, 1964). Grouping with kin is widely studied in the evolution of cooperation (e.g. in cooperative breeding species). In dynamic fissionfusion systems, such as fish shoals, however, a significant kin structure has not been found to date (e.g. Dowling and Moore, 1986; Peuhkuri and Seppa, 1998). Although guppies are capable of kin-recognition (Hain and Neff, 2007), only juveniles have been shown to be assorted by relatedness in the wild (Piyapong et al., 2011). Evidence for relatedness playing a role in the shoal structure of adult guppies has not been observed though (Croft et al., 2012). Although stable pair-wise associations between female guppies has been observed, the individuals tended to be only distantly related (Croft et al., 2012). Preferential assortment by relatedness in the wild shoals collected in the current study is therefore highly unlikely.

Preference to assort with familiar individuals has been observed in a number of fish species (e.g. Chivers et al., 1995; Griffiths and Magurran, 1997a,b). Association with familiars could be beneficial if it is related to reduced aggression, improved predator inspection behaviour and increased foraging success (Chivers et al., 1995; Morrell et al., 2008). Although guppies shoal preferentially with familiar individuals in some populations (Griffiths and Magurran, 1997a, 1997b; but see Godin et al., 2003), these studies generally focus only on the recognition and associations between familiar females (Magurran et al., 1994; Griffiths and Magurran, 1997a) or between males and females 
(mate choice of unfamiliar males) (Kelley et al., 1999), and not on male-male associations.

Although assortative shoaling based on body length and body colouration in the wild (Upper Aripo River) was not observed in the current study, it is possible that males in guppy shoals are nonetheless assorted based on other phenotypic traits, such as personality (e.g. propensity to cooperate) and/or familiarity, that I did not assess in the current study (as they were beyond the study's scope).

\section{Conclusions}

Overall, the current study has shown that, when given a dichotomous choice in the laboratory, male Trinidadian guppies from the Upper Aripo River population actively chose to associate with mixed-sex shoals that comprised a sexually-less attractive (smaller and less colourful) rival male than themselves. In exhibiting such a preference, a male guppy is apparently choosing a female that is near a less attractive sexual rival and thus may increase his reproductive success than otherwise, since female guppies generally prefer the more colourful and larger of available males.

Moreover, the current study is a good example of how an individual's social environment can affect its social association behaviour and in turn its relative sexual attractiveness and potentially its reproductive success. In general terms, it is an interesting example of how social information within groups can affect individual behavioural decision making, which can lead to non-random mating. Through this pathway, indirect genetic effects (IGE) - the effect of one individual's genes or 
phenotype on another individual's phenotype or fitness - can occur in highly social species (e.g. Moore et al., 1997; Wolf et al., 1998), such as the guppy.

Further, the ability of males to choose the social environment that increases their relative sexual attractiveness has evolutionary consequences as it contributes to the maintenance of variability in male secondary sexual ornamentation within populations and the potential for its further evolution (Gasparini et al., 2013).

\section{Future studies}

Since it is predicted that preferentially associating with a social group of relatively less attractive male competitors results in increased reproductive success for a focal male, a logical follow-up to my study would be to evaluate the actual mating and reproductive success of (offspring sired by) males that were perceived to be the most relatively more attractive in a social group compared to nearby rivals. In the field, when examining wild guppy shoals that are characterised by a highly dynamic fission-fusion nature, male assortment in shoal by either colour or length was not found in the current study. In future studies, it would be beneficial to investigate the occurrence and stability of social associations among known free-ranging males that are repeatedly observed over a longer span of time. This could be done, for example, by social network analysis of individuallymarked individuals occurring in fission-fusion groups in nature and relating their phenotypic traits (e.g. body size, body colouration) to their respective positions with social networks (cf. Croft et al., 2008). 


\section{REFERENCES}

Akaike, H. (1974). A new look at the statistical model identification. IEEE Trans. Autom. Control 19, 716-723.

Andersson, M.B. (1994). Sexual Selection (Princeton University Press).

Aplin, L.M., Farine, D.R., Morand-Ferron, J., Cole, E.F., Cockburn, A., and Sheldon, B.C. (2013). Individual personalities predict social behaviour in wild networks of great tits (Parus major). Ecol. Lett. 16, 1365-1372.

Archer, S.N., Endler, J.A., J.N., L., and Partridge, J.C. (1987). Visual pigment polymorphism in the guppy (Poecilia reticulata). Vision Res. 27, 1243-1252.

Ayala, F.J. (1974). Frequency-dependent selection. Annu. Rev. Ecol. Syst. 5, 115-138.

Badyaev, A.V., and Qvarnström, A. (2002). Putting sexual traits into the context of an organism: A life-history perspective in studies of sexual selection. The Auk 119, $301-310$.

Baird, T.A., Fox, S.F., and McCoy, J.K. (1997). Population differences in the roles of size and coloration in intra-and intersexual selection in the collared lizard, Crotaphytus collaris: influence of habitat and social organization. Behav. Ecol. 8, $506-517$.

Bateson, M., and Healy, S.D. (2005). Comparative evaluation and its implications for mate choice. Trends Ecol. Evol. 20, 659-664.

Bazzaz, F.A. (1991). Habitat selection in plants. Am. Nat. 137, S116-S130. 
Beehler, B.M., and Foster, M.S. (1988). Hotshots, hotspots, and female preference in the organization of lek mating systems. Am. Nat. 131, 203-219.

Billeter, J.-C., Jagadeesh, S., Stepek, N., Azanchi, R., and Levine, J.D. (2012). Drosophila melanogaster females change mating behaviour and offspring production based on social context. Proc. R. Soc. B Biol. Sci. 2417-2425.

Bisazza, A., Marconato, A., and Marin, G. (1989). Male mate preferences in the Mosquitofish Gambusia holbrooki. Ethology 83, 335-343.

Blumstein, D.T. and Daniel, J.C. (2007). Quantifying behavior the JWatcher way. Sinauer Associates, Inc., Sunderland, MA

Brooks, R., and Endler, J.A. (2001). Direct and indirect sexual selection and quantitative genetics of male traits in guppies (Poecilia reticulata). Evolution 55, 1002-1015.

Budaev, S.V. (1997). "Personality" in the guppy (Poecilia reticulata): A correlational study of exploratory behavior and social tendency. J. Comp. Psychol. 111, 399411.

Chivers, D.P., Brown, G.E., and Smith, R.J.F. (1995). Familiarity and shoal cohesion in fathead minnows (Pimephales promelas): implications for antipredator behaviour. Can. J. Zool. 73, 955-960.

Clutton-Brock, T.H., and Vincent, A.C.J. (1991). Sexual selection and the potential reproductive rates of males and females. Nature 351, 58-60.

Collins, S.A., Hubbard, C., and Houtman, A.M. (1994). Female mate choice in the zebra finch - the effect of male beak colour and male song. Behav. Ecol. Sociobiol. 35, $21-25$. 
Côté, I.M., and Hunte, W. (1989). Male and female mate choice in the Redlip blenny: why bigger is better. Anim. Behav. 38, 78-88.

Croft, D.P., Arrowsmith, B.J., Bielby, J., Skinner, K., White, E., Couzin, I.D., Magurran, A.E., Ramnarine, I., and Krause, J. (2003a). Mechanisms underlying shoal composition in the Trinidadian guppy, Poecilia reticulata. Oikos 100, 429-438.

Croft, D.P., Albanese, B., Arrowsmith, B.J., Botham, M., Webster, M., and Krause, J. (2003b). Sex-biased movement in the guppy (Poecilia reticulata). Oecologia 137, $62-68$.

Croft, D.P., Krause, J., and James, R. (2004). Social networks in the guppy (Poecilia reticulata). Proc. R. Soc. Lond. B Biol. Sci. 271, S516-S519.

Croft, D.P., Darden, S.K., and Ruxton, G.D. (2009a). Predation risk as a driving force for phenotypic assortment: a cross-population comparison. Proc. Biol. Sci. 276, 18991904.

Croft, D.P., Krause, J., Darden, S.K., Ramnarine, I.W., Faria, J.J., and James, R. (2009b). Behavioural trait assortment in a social network: patterns and implications. Behav. Ecol. Sociobiol. 63, 1495-1503.

Croft, D.P., Hamilton, P.B., Darden, S.K., Jacoby, D.M.P., James, R., Bettaney, E.M., and Tyler, C.R. (2012). The role of relatedness in structuring the social network of a wild guppy population. Oecologia 170, 955-963.

Danchin, É., Giraldeau, L.-A., Valone, T.J., and Wagner, R.H. (2004). Public information: From nosy neighbors to cultural evolution. Science 305, 487-491. 
Darden, S.K., James, R., Ramnarine, I.W., and Croft, D.P. (2009). Social implications of the battle of the sexes: sexual harassment disrupts female sociality and social recognition. Proc. R. Soc. B Biol. Sci. 276, 2651-2656.

Darwin, C. (1871). The Descent of man (D. Appleton and Company).

Dosen, L.D., and Montgomerie, R. (2004). Mate preferences by male guppies (Poecilia reticulata) in relation to the risk of sperm competition. Behav. Ecol. Sociobiol. 55, 266-271.

Dowling, T.E., and Moore, W.S. (1986). Absence of population subdivision in the common shiner, Notropis cornutus (Cyprinidae). Environ. Biol. Fishes 15, 151155.

Dubois, F., and Belzile, A. (2012). Audience effect alters male mating preferences in zebra finches (Taeniopygia guttata). PLoS ONE 7, 1-4.

Duckworth, R.A. (2009). The role of behavior in evolution: a search for mechanism. Evol. Ecol. 23, 513-531.

Dugatkin, L.A. (2009). Principles of Animal Behavior (W W Norton \& Company Incorporated).

Dugatkin, L.A., and Godin, J.-G.J. (1992). Reversal of female mate choice by copying in the guppy (Poecilia reticulata). Proc. Biol. Sci. 249, 179-184.

Dugatkin, L.A., and Godin, J.-G.J. (1993). Female mate copying in the guppy (Poecilia reticulata): age-dependent effects. Behav. Ecol. 4, 289-292.

Dugatkin, L.A., and Sargent, R.C. (1994). Male-male association patterns and female proximity in the guppy, Poecilia reticulata. Behav. Ecol. Sociobiol. 35, 141-145. 
Dzieweczynski, T.L., and Rowland, W.J. (2004). Behind closed doors: use of visual cover by courting male three-spined stickleback, Gasterosteus aculeatus. Anim. Behav. 68, 465-471.

Edvardsson, M., and Göran, A. (2000). Copulatory courtship and cryptic female choice in red flour beetles Tribolium castaneum. Proc. R. Soc. Lond. B Biol. Sci. 267, 559563.

Edward, J.A., and Chapman, T. (2011). The evolution and significance of male mate choice. Trends Ecol. Evol. 26, 647-654.

Endler, J.A. (1980). Natural selection on color patterns in Poecilia reticulata. Evolution 34, 76-91.

Endler, J.A. (1983). Natural and sexual selection on color patterns in poeciliid fishes. Environ. Biol. Fishes 9, 173-190.

Endler, J.A. (1991). Variation in the appearance of guppy color patterns to guppies and their predators under different visual conditions. Vision Res. 31, 587-608.

Endler, J.A., and Houde, A.E. (1995). Geographic variation in female preferences for male traits in Poecilia reticulata. Evolution 49, 456-468.

Evans, J.P, Pilastro, A., and Ramnarine, I.W. (2003). Sperm transfer through forced matings and its evolutionary implications in natural guppy (Peocilia reticulata) populations. Biol J Linn Soc 78.4, 605-612.

Fawcett, T.W., and Johnstone, R.A. (2003). Mate choice in the face of costly competition. Behav. Ecol. 14, 771-779.

Forsgren, E. (1992). Predation risk affects mate choice in a Gobiid fish. Am. Nat. 140, 1041-1049. 
Gasparini, C., Serena, G., and Pilastro, A. (2013). Do unattractive friends make you look better? Context-dependent male mating preferences in the guppy. Proc. R. Soc. B Biol. Sci. 280, 20123072.

Gerhardt, H.C. (1991). Female mate choice in treefrogs: static and dynamic acoustic criteria. Anim. Behav. 42, 615-635.

Godin, J.-G.J. (1986). Antipredator function of shoaling in teleost fishes: a selective review. Naturaliste can. $113,241-250$.

Godin, J.-G.J., and Auld, H.L. (2013). Covariation and repeatability of male mating effort and mating preferences in a promiscuous fish. Ecol. Evol. 3, 2020-2029.

Godin, J.-G.J., and Briggs, S.E. (1996). Female mate choice under predation risk in the guppy. Anim. Behav. 51, 117-130.

Godin, J.-G.J., and Hair, K.P.E. (2009). Mate-choice copying in free-ranging Trinidadian guppies (Poecilia reticulata). Behaviour 146, 1443-1461.

Godin, J.-G.J., Herdman, E.J.E., and Dugatkin, L.A. (2005). Social influences on female mate choice in the guppy, Poecilia reticulata: generalized and repeatable traitcopying behaviour. Anim. Behav. 69, 999-1005.

Gouzoules, S., Gouzoules, H., and Marler, P. (1984). Rhesus monkey (Macaca mulatta) screams: Representational signalling in the recruitment of agonistic aid. Anim. Behav. 32, 182-193.

Griffiths, S.W., and Magurran, A.E. (1997a). Familiarity in schooling fish: how long does it take to acquire? Anim. Behav. 53, 945-949. 
Griffiths, S.W., and Magurran, A.E. (1997b). Schooling preferences for familiar fish vary with group size in a wild guppy population. Proc. R. Soc. Lond. B Biol. Sci. 264, $547-551$.

Guevara-Fiore, P., Stapley, J., and Watt, P.J. (2010). Mating effort and female receptivity: how do male guppies decide when to invest in sex? Behav. Ecol. Sociobiol. 64, 1665-1672.

Hain, T.J.A., and Neff, B.D. (2007). Multiple paternity and kin recognition mechanisms in a guppy population. Mol. Ecol. 16, 3938-3946.

Hamilton, W.D. (1964). The genetical evolution of social behaviour. I. J. Theor. Biol. 7, $1-16$.

Herdman, E.J.E., Kelly, C.D., and Godin, J.-G.J. (2004). Male mate choice in the guppy (Poecilia reticulata): Do males prefer larger females as mates? Ethology 110, 97111.

Honěk, A. (1993). Intraspecific variation in body size and fecundity in insects: a general relationship. Oikos 66, 483-492.

Houde, A.E. (1988). The effects of female choice and male-male competition on the mating success of male guppies. Anim. Behav. 36, 888-896.

Houde, A.E. (1992). Heredity - Abstract of article: Sex-linked heritability of a sexually selected character in a natural population of Poecilia reticulata (Pisces: Poeciliidae) (guppies). Heredity 69, 229-235.

Houde, A.E. (1997). Sex, color, and mate choice in guppies (Princeton University Press). 
Houde, A.E., and Hankes, M.A. (1997). Evolutionary mismatch of mating preferences and male colour patterns in guppies. Anim. Behav. 53, 343-351.

Hughes, K.A., Du, L., Rodd, F.H., and Reznick, D.N. (1999). Familiarity leads to female mate preference for novel males in the guppy, Poecilia reticulata. Anim. Behav. $58,907-916$.

Hughes, K.A., Houde, A.E., Price, A.C., and Rodd, F.H. (2013). Mating advantage for rare males in wild guppy populations. Nature 503, 108-110.

Jennions, M.D., and Petrie, M. (1997). Variation in mate choice and mating preferences: A review of causes and consequences. Biol. Rev. 72, 283-327.

Jeswiet, S.B., and Godin, J.-G.J. (2011). Validation of a Method for Quantifying Male Mating Preferences in the Guppy (Poecilia reticulata). Ethology 117, 422-429.

Jeswiet, S.B., Lee-Jenkins, S.S.Y., Ramnarine, I.W., and Godin, J.-G.J. (2011). Sperm competition risk and mate choice in male Trinidadian guppies, Poecilia reticulata. Anim. Behav. 81, 639-644.

Jeswiet, S.B., Lee-Jenkins, S.S.Y., and Godin, J.-G.J. (2012). Concurrent effects of sperm competition and female quality on male mate choice in the Trinidadian guppy (Poecilia reticulata). Behav. Ecol. 23, 195-200.

Jirotkul, M. (1999). Operational sex ration influences female preference and male-male competition in guppies. Anim. Behav. 58, 287-294.

Jones, K.M., Monaghan, P., and Nager, R.G. (2001). Male mate choice and female fecundity in zebra finches. Anim. Behav. 62, 1021-1026. 
Jordan, L.A., Kokko, Hanna, and Kasumovic, M. (2014). Reproductive foragers: Male spiders choose mates by selecting among competitive environments. Am. Nat. 183, 638-649.

Karino, K., and Haijima, Y. (2001). Heritability of male secondary sexual traits in feral guppies in Japan. J. Ethol. 19, 33-37.

Kelley, J.L., Graves, J.A., and Magurran, A.E. (1999). Familiarity breeds contempt in guppies. Nature 401, 661-662.

Kelly, C.D., Godin, J.-G.J., and Wright, J.M. (1999). Geographic variation in multiple paternity within natural populations of the guppy (Poecilia reticulata). Proc. R. Soc. Lond. B Biol. Sci. 266, 2403-2408.

Kirkpatrick, M., and Dugatkin, L.A. (1994). Sexual selection and the evolutionary effects of copying mate choice. Behav. Ecol. Sociobiol. 34, 443-449.

Kodric-Brown, A. (1985). Female preference and sexual selection for male coloration in the guppy (Poecilia reticulata). Behav. Ecol. Sociobiol. 17, 199-205.

Kodric-Brown, A. (1989). Dietary carotenoids and male mating success in the guppy: an environmental component to female choice. Behav. Ecol. Sociobiol. 25, 393-401.

Kodric-Brown, A., and Johnson, S.C. (2002). Ultraviolet reflectance patterns of male guppies enhance their attractiveness to females. Anim. Behav. 63, 391-396.

Kodric-Brown, A., and Nicoletto, P.F. (2001). Female choice in the guppy (Poecilia reticulata): the interaction between male color and display. Behav. Ecol. Sociobiol. $50,346-351$.

Krause, J., and Ruxton, G.D. (2002). Living in groups (Oxford University Press). 
Krause, J., Hoare, D.J., Croft, D., Lawrence, J., Ward, A., Ruxton, G.D., Godin, J.-G.J., and James, R. (2000). Fish shoal composition: mechanisms and constraints. Proc. R. Soc. Lond. B Biol. Sci. 267, 2011-2017.

Krause, J., James, R., and Croft, D.P. (2010). Personality in the context of social networks. Philos. Trans. R. Soc. B Biol. Sci. 365, 4099-4106.

Laland, K.N., Odling-Smee, F.J., and Feldman, M.W. (1999). Evolutionary consequences of niche construction and their implications for ecology. Proc. Natl. Acad. Sci. 96, $10242-10247$.

Landeau, L., and Terborgh, J. (1986). Oddity and the "confusion effect" in predation. Anim. Behav. 34, 1372-1380.

LeMaster, M.P., and Mason, R.T. (2002). Variation in a female sexual attractiveness pheromone controls male mate choice in Garter snakes. J. Chem. Ecol. 28, 12691285.

Lewis, R.J. (2008). Social influences on group membership in Propithecus verreauxi verreauxi. Int. J. Primatol. 29, 1249-1270.

Long, K.D., and Houde, A.E. (1989). Orange spots as a visual cue for female mate choice in the guppy (Poecilia reticulata). Ethology 82, 316-324.

Magurran, A.E. (2005). Evolutionary ecology: The Trinidadian guppy (Oxford University Press).

Magurran, A.E., and Seghers, B.H. (1994). Sexual conflict as a consequence of ecology: Evidence from Guppy, Poecilia reticulata, populations in Trinidad. Proc. R. Soc. Lond. B Biol. Sci. 255, 31-36. 
Magurran, A.E., Seghers, B.H., Shaw, P.W., and Carvalho, G.R. (1994). Schooling preferences for familiar fish in the guppy, Poecilia reticulata. J. Fish Biol. 45, 401406.

Makowicz, A.M., Plath, M., and Schlupp, I. (2010). Male guppies (Poecilia reticulata) adjust their mate choice behaviour to the presence of an audience. Behaviour 147, $1657-1674$.

MATLAB and Statistics Toolbox Release R2013a, The MathWorks, Inc., Natick, Massachusetts, United States.

Matos, R.J., and Schlupp, I. (2005). Performing in front of an audience: signallers and the social environment. In: Animal communication networks. Edited by P.K. McGregor, pp.63-79.

McGlothlin, J.W., Moore, A.J., Wolf, J.B., and Brodie III, E.D. (2010). Interacting phenotypes and the evolutionary process. Iii. Social Evolution. Evolution 64, 25582574.

Moore, A.J., Brodie, E.D., III, and Wolf, J.B. (1997). Interacting phenotypes and the evolutionary process: I. Direct and indirect genetic effects of social interactions. Evolution 51, 1352-1362.

Morrell, L.J., Croft, D.P., Dyer, J.R.G., Chapman, B.B., Kelley, J.L., Laland, K.N., and Krause, J. (2008). Association patterns and foraging behaviour in natural and artificial guppy shoals. Anim. Behav. 76, 855-864.

Neff, B.D., Pitcher, T.E., and Ramnarine, I.W. (2008). Inter-population variation in multiple paternity and reproductive skew in the guppy. Mol. Ecol. 17, 2975-2984. 
Odling-Smee, F.J., Laland, K.N., and Feldman, M.W. (1996). Niche construction. Am. Nat. 147, 641-648.

Oh, K.P., and Badyaev, A.V. (2010). Structure of social networks in a passerine bird: Consequences for sexual selection and the evolution of mating strategies. Am. Nat. 176, E80-E89.

Ojanguren, A.F., and Magurran, A.E. (2007). Male harassment reduces short-term female fitness in guppies. Behaviour 144, 503-514.

Orians, G.H., and Wittenberger, J.F. (1991). Spatial and temporal scales in habitat selection. Am. Nat. 137, S29-S49.

Parker, G.A., Ball, M.A., Stockley, P., and Gage, M.J.G. (1996). Sperm competition games: individual assessment of sperm competition intensity by group spawners. Proc. R. Soc. Lond. B Biol. Sci. 263, 1291-1297.

Peuhkuri, N., and Seppa, P. (1998). Do three-spined stickleback groups with kin? Ann. Zool. Fenn. 35, 21-27.

Pike, T.W., Samanta, M., Lindström, J., and Royle, N.J. (2008). Behavioural phenotype affects social interactions in an animal network. Proc. R. Soc. B Biol. Sci. 275, $2515-2520$.

Pilastro, A.,and Bisaza, A. (1999). Insamination efficiency of two alternative male mating tactics in the guppy Poecilia reticulata. Proc. R. Soc. B Biol. Sci. 266, 1887-1891.

Pilastro, A., Simonato, M., Bisazza, A., and Evans, J.P. (2004). Cryptic female preference for colorful males in guppies. Evolution 58, 665-669. 
Pitcher, T.E., and Evans, J.P. (2001). Male phenotype and sperm number in the guppy (Poecilia reticulata). Can. J. Zool. 79, 1891-1896.

Pitcher, T.E., Rodd, F.H., and Rowe, L. (2007). Sexual colouration and sperm traits in guppies. J. Fish Biol. 70, 165-177.

Pitcher, T.J. and Parrish, J.K. (1993). Functions of shoaling behaviour in teleosts. In: Behaviour of teleost fishes, $2^{\text {nd }}$ edn, edited by T.J. Pitcher, pp. 363-439.

Pitcher, T.J., Green, D.A., and Magurran, A.E. (1986). Dicing with death: predator inspection behaviour in minnow shoals. J. Fish Biol. 28, 439-448.

Pitnick, S., and Brown, W.D. (2000). Criteria for demonstrating female sperm choice. Evolution 54, 1052-1056.

Piyapong, C., Butlin, R.K., Faria, J.J., Scruton, K.J., Wang, J., and Krause, J. (2011). Kin assortment in juvenile shoals in wild Guppy populations. Heredity 106, 749-756.

Plath, M., Blum, D., Schlupp, I., and Tiedemann, R. (2008). Audience effect alters mating preferences in a livebearing fish, the Atlantic molly, Poecilia mexicana. Anim. Behav. 75, 21-29.

Plath, M., Kromuszczynski, K., and Tiedemann, R. (2009). Audience effect alters male but not female mating preferences. Behav. Ecol. Sociobiol. 63, 381-390.

Procter, D.S., Moore, A.J., and Miller, C.W. (2012). The form of sexual selection arising from male-male competition depends on the presence of females in the social environment. J. Evol. Biol. 25, 803-812. 
Punzalan, D., Rodd, F.H., and Rowe, L. (2008). Contemporary sexual selection on sexually dimorphic traits in the ambush bug Phymata americana. Behav. Ecol. 19, 860-870.

R Development Core Team (2013). R: A Language and Environment for Statistical Computing, version 3.0.2. Vienna, Austria: R Foundation for Statistical Computing (http://cran.r-project.org/).

Reynolds, J.D., and Gross, M.R. (1992). Female mate preference enhances offspring growth and reproduction in a fish, Poecilia reticulata. Proc. R. Soc. Lond. B Biol. Sci. $250,57-62$.

Reznick, D., and Endler, J.A. (1982). The impact of predation on life history evolution in Trinidadian guppies (Poecilia reticulata). Evolution 36, 160-177.

Ruckstuhl, K.E., and Neuhaus, P. (eds). (2005). Sexual segregation in vertebrates: ecology of the two sexes. Cambridge University Press, Cambridge.

Seehausen, O., and Alphen, J.J.M. van (1998). The effect of male coloration on female mate choice in closely related Lake Victoria cichlids (Haplochromis nyererei complex). Behav. Ecol. Sociobiol. 42, 1-8.

Seyfarth, R.M., Cheney, D.L., and Marler, P. (1980). Monkey responses to three different alarm calls: evidence of predator classification and semantic communication. Science $210,801-803$.

Sih, A., Bell, A., and Johnson, J.C. (2004). Behavioral syndromes: an ecological and evolutionary overview. Trends Ecol. Evol. 19, 372-378. 
Smith, E.J., Partridge, J.C., Parsons, K.N., White, E.M., Cuthill, I.C., Bennett, A.T.D., and Church, S.C. (2002). Ultraviolet vision and mate choice in the guppy (Poecilia reticulata). Behav. Ecol. 13, 11-19.

Sol, D., Stirling, D.G., and Lefebvre, L. (2005). Behavioral drive or behavioral inhibition in evolution: Subspecific diversification in holarctic passerines. Evolution 59, 2669-2677.

Song, Z, Boenke, M.C., and Rodd, F.H. (2011). Interpopulation differences in shoaling behaviour in Guppies (Poecilia reticulata): Roles of social environment and population origin. Ethology 117, 10090-1018.

Stamps, J.A., Krishnan, V.V., and Reid, M.L. (2005). Search costs and habitat selection by dispersers. Ecology 86, 510-518.

Thorpe, A., Douglas, R.H., and Truscott, R.J.W. (1993). Spectral transmission and shortwave absorbing pigments in the fish lens-I. Phylogenetic distribution and identity. Vision Res. 33, 289-300.

Vakirtzis, A. (2011). Mate choice copying and non-independent mate choice: A critical review. Ann. Zool. Fenn. 48, 91-107.

Valone, T.J. (2007). From eavesdropping on performance to copying the behavior of others: a review of public information use. Behav. Ecol. Sociobiol. 62, 1-14.

Valone, T.J., and Templeton, J.J. (2002). Public information for the assessment of quality: a widespread social phenomenon. Philos. Trans. R. Soc. Lond. B. Biol. Sci. $357,1549-1557$. 
Waite, T.A. (2001). Background context and decision making in hoarding gray jays. Behav. Ecol. 12, 318-324.

Ward, A.J.W., and Krause, J. (2001). Body length assortative shoaling in the European minnow, Phoxinus phoxinus. Anim. Behav. 62, 617-621.

Watt, P.J., Shohet, A.J., and Renshaw, K. (2001). Female choice for good genes and sexbiased broods in guppies. J. Fish Biol. 59, 843-850.

Webster, M.M., and Ward, A.J.W. (2011). Personality and social context. Biol. Rev. 86, 759-773.

Weese, D.J., Gordon, S.P., Hendry, A.P., and Kinnison, M.T. (2010). Spatiotemporal variation in linear natural selection on body color in wild guppies (Poecilia reticulata). Evolution 64, 1802-1815.

Westneat, D.F., Walters, A., McCarthy, T.M., Hatch, M.I., and Hein, W.K. (2000). Alternative mechanisms of nonindependent mate choice. Anim. Behav. 59, 467476.

White, E.M., Partridge, J.C., and Church, S.C. (2003). Ultraviolet dermal reflexion and mate choice in the guppy, Poecilia reticulata. Anim. Behav. 65, 693-700.

Wilson, A.D.M., Krause, S., Dingemanse, N.J., and Krause, J. (2013). Network position: a key component in the characterization of social personality types. Behav. Ecol. Sociobiol. 67, 163-173.

Wolf, J.B., Brodie III, E.D., Cheverud, J.M., Moore, A.J., and Wade, M.J. (1998). Evolutionary consequences of indirect genetic effects. Trends Ecol. Evol. 13, 6469. 
Ziege, M., Mahlow, K., Hennige-Schulz, C., Kronmarck, C., Tiedemann, R., Streit, B., and Plath, M. (2009). Audience effects in the Atlantic molly (Poecilia mexicana)prudent male mate choice in response to perceived sperm competition risk? Front. Zool. 6, 17. 


\section{APPENDICES}

Table A1. Selection results for the candidate multiple regression models testing for the effects of body length and colour differences between the focal male, preferred stimulus male and non-preferred stimulus male ('relative hypothesis'), and the absolute colour scores for the three males ('absolute hypothesis'), on the time that focal males spent associating with their preferred mixed-sex stimulus shoal. The results are sorted by $\triangle \mathrm{AICc}$ values and AICc weights $\left(\mathrm{W}_{i}\right)$. The model set includes 11 models. Parameters that were the least significant were elminated, starting with the interaction terms, leading to a new model each.

\begin{tabular}{|c|c|c|c|c|c|}
\hline \# & variables & $\mathbf{K}$ & $\mathbf{A I C}_{\mathbf{C}}$ & $\Delta \mathrm{AIC}_{\mathrm{C}}$ & $\mathbf{W}_{i}$ \\
\hline M11 & $\begin{array}{l}\text { Pdifflength*Pdiffcolour+ } \\
\text { lengthfemaleNP }\end{array}$ & 6 & 700.128 & 0.00 & 0.6288 \\
\hline M10 & $\begin{array}{l}\text { Pdifflength*Pdiffcolour+ } \\
\text { lengthfemaleNP+ } \\
\text { NPstimcolour }\end{array}$ & 7 & 702.181 & 2.05 & 0.2253 \\
\hline M9 & $\begin{array}{l}\text { Pdifflength*Pdiffcolour }+ \\
\text { lengthfemaleNP+focalcolour }+ \\
\text { NPstimcolour }\end{array}$ & 8 & 704.413 & 4.29 & 0.0738 \\
\hline M8 & $\begin{array}{l}\text { Pdifflength*Pdiffcolour+ } \\
\text { lengthfemaleNP+focalcolour+ } \\
\text { Pstimcolour+NPstimcolour }\end{array}$ & 9 & 705.428 & 5.30 & 0.0444 \\
\hline M7 & $\begin{array}{l}\text { Pdifflength*Pdiffcolour }+ \\
\text { PNPdiffcolour+lengthfemaleNP+focalcolour }+ \\
\text { Pstimcolour+NPstimcolour }\end{array}$ & 10 & 707.208 & 7.08 & 0.0183 \\
\hline M6 & $\begin{array}{l}\text { Pdifflength*Pdiffcolour+NPdiffcolour+ } \\
\text { PNPdiffcolour+lengthfemaleNP+focalcolour+ } \\
\text { Pstimcolour+NPstimcolour }\end{array}$ & 11 & 709.282 & 9.15 & 0.0065 \\
\hline M5 & $\begin{array}{l}\text { Pdifflength*Pdiffcolour+NPdiffcolour+ } \\
\text { PNPdifflength+PNPdiffcolour+lengthfemaleNP+ } \\
\text { focalcolour+Pstimcolour+NPstimcolour }\end{array}$ & 12 & 711.698 & 11.57 & 0.0019 \\
\hline M4 & $\begin{array}{l}\text { Pdifflength*Pdiffcolour+NPdifflength+NPdiffcolour+ } \\
\text { PNPdifflength+PNPdiffcolour+lengthfemaleNP+ } \\
\text { focalcolour+Pstimcolour+NPstimcolour }\end{array}$ & 13 & 713.951 & 13.82 & 0.0006 \\
\hline M3 & $\begin{array}{l}\text { Pdifflength*Pdiffcolour+NPdifflength+NPdiffcolour+ } \\
\text { PNPdifflength+PNPdiffcolour+lengthfemaleP+ } \\
\text { lengthfemaleNP+focalcolour+Pstimcolour+NPstimcol } \\
\text { our }\end{array}$ & 14 & 716.438 & 16.31 & 0.0002 \\
\hline M2 & $\begin{array}{l}\text { Pdifflength*Pdiffcolour+NPdifflength+NPdiffcolour+ } \\
\text { PNPdifflength*PNPdiffcolour+lengthfemaleP+ } \\
\text { lengthfemaleNP+focalcolour+Pstimcolour+NPstimcol }\end{array}$ & 15 & 716.531 & 16.40 & 0.0002 \\
\hline M1 & $\begin{array}{l}\text { Pdifflength*Pdiffcolour+NPdifflength*NPdiffcolour+ } \\
\text { PNPdifflength*PNPdiffcolour+lengthfemaleP+ } \\
\text { lengthfemaleNP+focalcolour+Pstimcolour+NPstimcol } \\
\text { our }\end{array}$ & 16 & 716.998 & 18.87 & 0.0001 \\
\hline
\end{tabular}


Notes: $\mathrm{k}=$ number of estimated parameters; $\mathrm{AIC}_{\mathrm{C}}=-2 \mathrm{xlog}$-likelihood $+2 \mathrm{k}(\mathrm{k}+1) /(\mathrm{n}-\mathrm{k}-1)$, where $\mathrm{n}=$ sample size; $\Delta \mathrm{AIC}_{\mathrm{C}}=\mathrm{AIC}_{\mathrm{C}}-\mathrm{AIC}_{\text {min }} ; \mathrm{W}_{i}=\mathrm{e}^{\wedge}\left(-0.5 \mathrm{x} \Delta \mathrm{AIC}_{\mathrm{Ci}}\right) / \Sigma \mathrm{e}^{\wedge}\left(-0.5 \mathrm{x} \Delta \mathrm{AIC}_{\mathrm{Ci}}\right)$. Pdifflength $=$ difference in length between focal and preferred stimulus male relative to focal male; Pdiffcolour $=$ difference in colour between focal and preferred stimulus male relative to focal male; NPdifflength= difference in length between focal and non-preferred stimulus male relative to focal male; NPdiffcolour = difference in colour between focal and non-preferred stimulus male relative to focal male; PNPdifflength= difference in length between preferred and non-preferred stimulus male relative to non-preferred stimulus male; PNPdiffcolour $=$ difference in colour between preferred and non-preferred stimulus male relative to non-preferred stimulus male; lengthfemale $\mathrm{P}=$ length of female on preferred side; lengthfemaleNP=length of female on nonpreferred side; focalcolour $=$ colour score of focal male; ; Pstimcolour $=$ colour score of preferred stimulus male; NPstimcolour=colour score of the non-preferred stimulus male. 
Table A2. Results for the comparison (competing) multiple regression model (Model M2) testing for the effects of the absolute body lengths and colours of the non-preferred stimulus male and preferred stimulus male on the time that focal males spent associating with their preferred mixed-sex stimulus shoal. Shown are the model's equation and the model'sparameters, estimates, $\mathrm{p}$-values for each coefficient, multiple R-squared and adjusted R-squared, and p-value.

\begin{tabular}{|c|c|c|}
\hline \multicolumn{3}{|c|}{$\begin{array}{l}\text { Model: } \operatorname{lm}(\text { sqrt(timePside)) } \sim \text { NPstimlength*NPstimcolour+Pstimlength*Pstimcolour+ } \\
\text { lengthfemaleNP+lengthfemaleP) }\end{array}$} \\
\hline Coeffecients & estimate & p-value \\
\hline (intercept) & 17.470 & 0.246 \\
\hline NPstimlength & 0.001 & 0.997 \\
\hline NPstimcolour & 11.674 & 0.935 \\
\hline Pstimlength & 0.066 & 0.874 \\
\hline Pstimcolour & 111.0776 & 0.464 \\
\hline lengthfemaleNP & 0.027 & 0.930 \\
\hline lengthfemaleP & 0.086 & 0.780 \\
\hline NPstimlength*NPstimcolour & 0.096 & 0.986 \\
\hline Pstimlength*Pstimcolour & -4.141 & 0.487 \\
\hline \multirow[t]{2}{*}{ Multiple R-squared: 0.0445} & \multicolumn{2}{|c|}{ Adjusted R-squared: $\mathbf{- 0 . 0 1 7 7}$} \\
\hline & & p-value: 0.6771 \\
\hline \multicolumn{3}{|c|}{$\begin{array}{l}\text { Notes: } \text { sqrt = square root; timePside }=\text { absolute time spent on preferred side; NPstimlength=length } \\
\text { of non-preferred stimulus male; NPstimcolour }=\text { colour score of non-preferred stimulus male; } \\
\text { Pstimlength=length of preferred stimulus male; Pstimcolour=colour score of preferred stimulus } \\
\text { male; lengthfemaleNP=length of female on non-preferred side; lengthfemaleP=length of female } \\
\text { on preferred side; NPstimlength:NPstimcolour=interaction of length and colour of non-preferred } \\
\text { stimulus male; Pstimlength:Pstimcolour=interaction of length and colour of preferred stimulus } \\
\text { male; } * \text { indicates significance of coffecient }(\mathrm{p} \leq 0.05) .\end{array}$} \\
\hline
\end{tabular}


Table A3. Results of the AIC model selection process comparing two competing alternative models. One model (M11) tested for the effects of body length and colour differences between focal male and the preferred stimulus male on the time that focal males spent associating with their preferred mixed-sex stimulus shoal (dependent variable). The other model (M2) tested for the effects of the absolute length and colour scores of the non-preferred and preferred stimulus males on the dependent variable. The results are sorted by $\triangle \mathrm{AICc}$ values and AICc weights $\left(\mathrm{W}_{i}\right)$. Parameters that were the least significant were elminated, starting with the interaction terms, leading to a new model each.

\begin{tabular}{llllll}
\hline $\begin{array}{l}\text { Model } \\
\#\end{array}$ & variables & $\mathbf{K}$ & $\mathbf{A I C}_{\mathbf{C}}$ & $\mathbf{\Delta} \mathbf{A I C}_{\mathbf{C}}$ & $\mathbf{W}_{\boldsymbol{i}}$ \\
\hline M11 & $\begin{array}{l}\text { Pdifflength*Pdiffcolour+ } \\
\text { lengthfemaleNP }\end{array}$ & 6 & 0.000 & 0.000 & 0.9994 \\
M2 & $\begin{array}{l}\text { NPstimlength*NPstimcolour+Pstimlength* } \\
\text { Pstimcolour+ } \\
\text { lengthfemaleNP+lengthfemaleP }\end{array}$ & 10 & 14.954 & 14.954 & 0.0006 \\
\hline
\end{tabular}

Notes: $\mathrm{k}=$ number of estimated parameters; $\mathrm{AIC}_{\mathrm{C}}=-2 \mathrm{x} \log$-likelihood $+2 \mathrm{k}(\mathrm{k}+1) /(\mathrm{n}-\mathrm{k}-1)$, where $\mathrm{n}=$ sample size; $\Delta \mathrm{AIC}_{\mathrm{C}}=\mathrm{AIC}_{\mathrm{C}}-\mathrm{AIC}_{\min } ; \mathrm{W}_{i}=\mathrm{e}^{\wedge}\left(-0.5 \mathrm{x} \Delta \mathrm{AIC}_{\mathrm{Ci}}\right) / \Sigma \mathrm{e}^{\wedge}\left(-0.5 \mathrm{x} \Delta \mathrm{AIC}_{\mathrm{Ci}}\right)$. Pdifflength $=$ difference in length between focal and preferred stimulus male relative to focal male; Pdiffcolour $=$ difference in colour between focal and preferred stimulus male relative to focal male; lengthfemale $\mathrm{P}=$ length of female on preferred side; lengthfemaleNP=length of female on nonpreferred side; Pstimcolour $=$ colour score of preferred stimulus male; NPstimcolour $=$ colour score of the non-preferred stimulus male. 


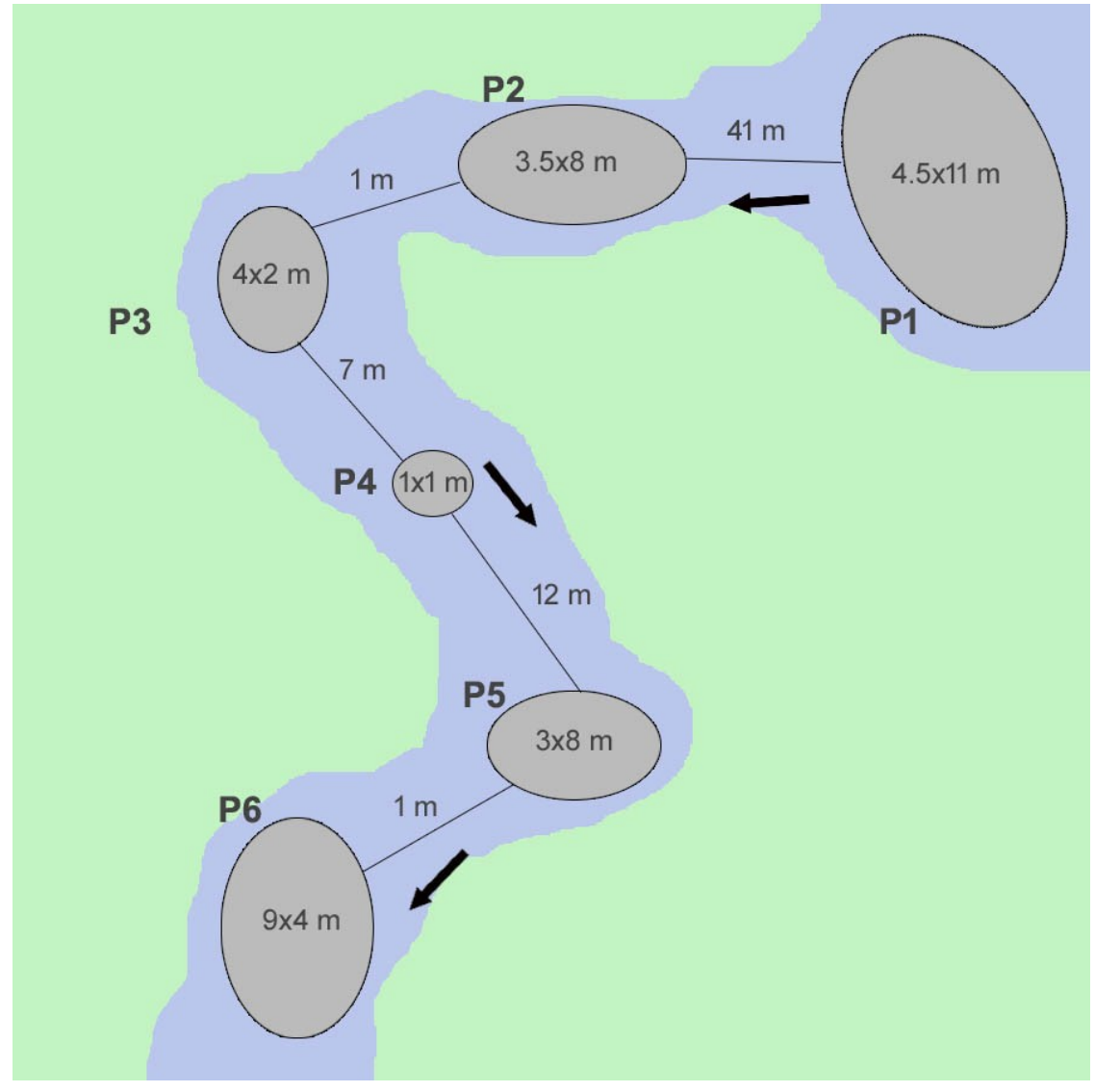

Figure A1. Schematic diagram of pools sampled for mixed-sex shoals of guppies in the Upper Aripo River, Trinidad. The identification number and maximum linear dimensions (width $\mathrm{x}$ length, in metres) of each pool, and the distances $(\mathrm{m})$ between them, are indicated. Shallow stream riffle sections separated adjacent pools. Arrows indicate the direction of water flow. The diagram is not to scale. 


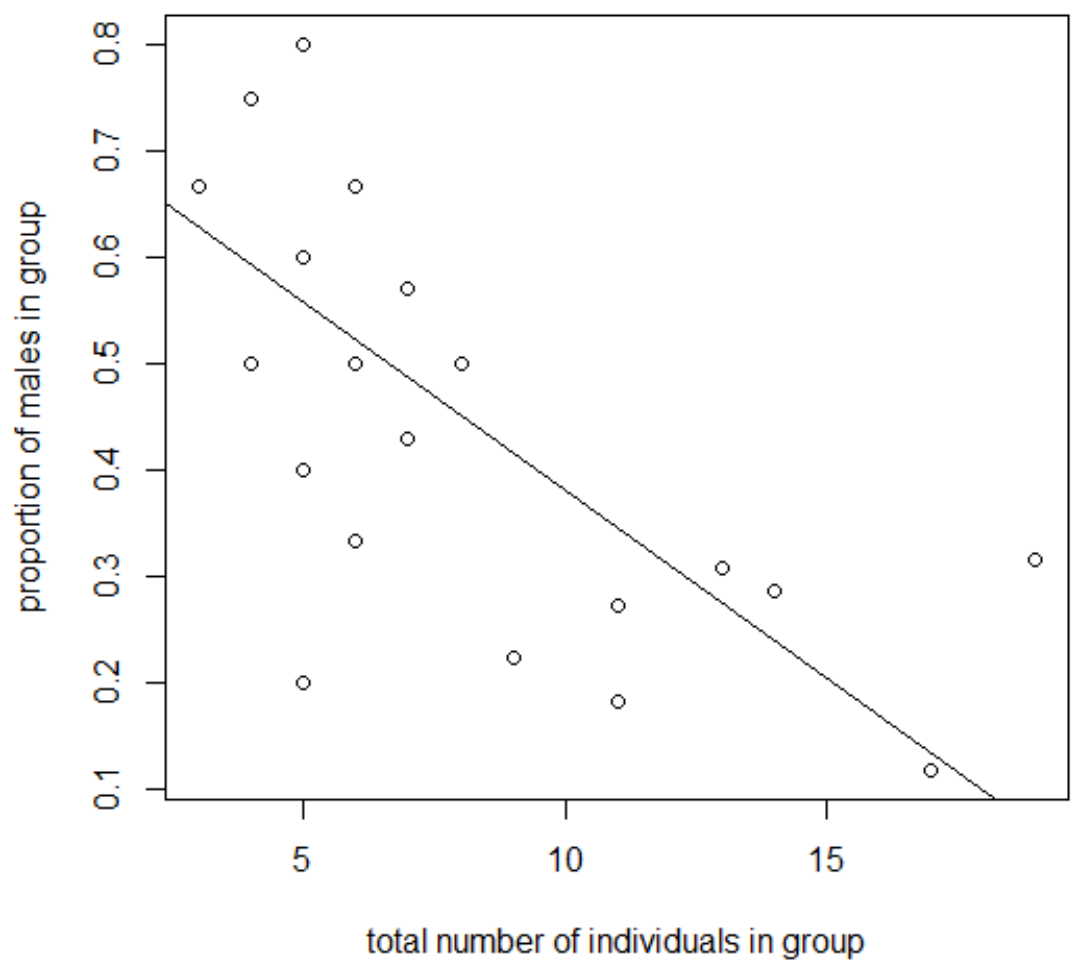

Figure A2. Proportion of adult males in free-ranging mixed sex shoals of guppies $(\mathrm{n}=67)$ collected in the in the Upper Aripo River, Trinidad in relation to the total number of individuals (adult males + females) in the shoals. Line-of-best-fit was obtained by linear regression $(r=-0.698, p<0.001)$. 